\title{
RELACIONES DE PRODUCCIÓN EN DOS ÁREAS AGRÍCOLAS DE BRASIL
}

\author{
Geraldo Müller * \\ Centro Brasileiro de Analisis \\ e Planejamento
}

\section{I. . INTRODUCCIÓN}

EL PRESENTE tRABajo es un estudio de dos áreas agrícolas con estructuras diferentes: una, con base campesina, vinculada de manera orgánica a la economía agropecuaria de recolección, mercantil y otra en proceso de extirpación de los restos del antiguo régimen de trabajo conocido como el "colonato". ${ }^{1}$ Se trata de mostrar los mecanismos de cada estructura, la naturaleza y la forma de sus movimientos. De manera concreta, en el área campesina hay una tendencia a reponer los elementos básicos del complejo latifundio-minifundio, forma en que se presenta el mundo campesino, y en cierto sentido, a reforzar al mismo tiempo esa reposición gracias a la expansión del capitalismo en el sistema nacional y en el área campesina. Ya en esta área, donde el número de obreros agrícolas aumenta al sustituir al colono, el capitalismo penetra y se afirma en el proceso productivo y genera un ejército de reserva con residencia en los "barrios rurales" y en las periferias de las ciudades.

Ambas estructuras agrícolas se hallan vinculadas de modo subalterno al desarrollo brasileño alrededor de la industria, es decir, subordinadas a la expansión del capital. Sin embargo, tal movimiento no es idéntico en las dos áreas. Si en una el capital no penetró en la esfera de la producción, no subordinó realmente el trabajo al capital, si bien se apodera

* Agradezco las valiosas sugerencias a este trabajo de Juarez R. B. Lopes, Octavio Iani y Paulo I. Singer.

1 El colonato surge en la Historia con la caída de la esclavitud. Abolido el tráfico en 1850, el crecimiento de la masa de mano de obra negra depende de su crecimiento vegetativo; su elevada tasa de mortalidad, sumada a su rebeldía, la tornan "inadecuada" al proceso productivo. Pasa a ser sustituida entonces por inmigrantes europeos que viven en las haciendas y se responsabilizan de cierto número de cafetos, al mismo tiempo que se les permite la cría de cierto número de animales y el uso de las áreas libres del cafetal (entre una hilera y otra); el producto de los cultivos de subsistencia podía ser propiedad exclusiva suya o repartida con el propictario. Por lo tanto, el colono recibía parte de sus medios de vida bajo la forma de salatio y parte bajo la forma de producción. 
del excedente en la esfera de la circulación, en la otra ese proceso de subordinación real se extiende. Por otro lado, si en esta última la tierra es en esencia un medio de valorización del capital, en aquélla es en esencia un medio para que la masa campesina pueda subsistir $y$, al mismo tiempo, provea trabajo para la economía mercantil.

En ese contexto, a modo de sugerencias, se hacen algunas consideraciones sobre la dinámica demográfica en áreas agrícolas diferentes.

\section{LAS ÁREAS DE ESTUdio}

La cuenca del Parnaíba abarca un área de 354176 kilómetros cuadrados (1970), ocupa todo el estado de Piauí, área diminuta del noroeste cearense y buena parte del este maranhense. En 1970 contaba con una población de más de 2.6 millones de personas, con menos de $25 \%$ en núcleos de dos mil y más personas. De 165 "ciudades", apenas nueve tenían más de 10000 habitantes; y más de dos millones constituyen la población rural y semirural (esta última comprende pequeñas ciudades y pueblos de hasta dos mil habitantes).

En términos generales, el carácter de la cuenca se revela por su uniformidad: amplia base campesina con producción agraria mercantil, por lo que "lo rural" y "lo urbano" se presentan interpenetrados, evidencia de una débil división social del trabajo. ${ }^{2}$

La región de la alta sorocabana de Assis, ${ }^{3}$ tiene una superficie de 6983 kilómetros cuadrados (1968) con un poco más de 189000 habitantes (1970); y se encuentra situada en la meseta media del Estado de São Paulo, al suroeste.

En 1970, más de 96000 habitantes vivían en localidades urbanas, o sea $51 \%$ (si se eliminan los núcleos menores, de hasta 500 personas, la proporción se reduce a $50 \%$. Sin embargo, como se verá después, la naturaleza de esos pequeños núcleos difiere de aquellos de hasta 2000 habitantes de la Cuenca; se trata, en Assis, de "barrios rurales", mientras que en la Cuenca, de residencias de campesinos y sede del artesanado). Se encuentra aquí una clara división del trabajo social entre campo y ciudad y una división en el mismo sector agropecuario; y por otro lado se localiza la instalación de verdaderas empresas rurales que en

2 Para el análisis de esta área agrícola se aprovechó el estudio hecho por Paulo Singer, Mirna Ayres I. Gonçalves y Elizabeth Machado de Oliveira, "Projeçao da População da Bacia do Parnaíba", como también el trabajo de Juarez R. B. Lopes y Geraldo Müller, "Condiçoes Sociais da Bacia do Parnaíba", ambos del CEBRAP, mimeografiados, 1974.

3 Se trata de una de las 361 microregiones homogéneas en que fue dividido el país. Véase "Divisão do Brasil em Micro-regiões homogêneas-1968, Río de Janeiro, IBGE, 1968. La microregión homogénea de Assis se compone de 15 municipios que presentan, según criterios y estudios del IBGE, cierta homogeneidad mínima en relación a la agrupación de otros conjuntos de municipios. 
cierta medida expulsan a los elementos restantes del régimen de "colonato"."

\section{LOS CAMPESINOS DE LA CUENCA DEL RÍO PARNAÍBA}

Los campesinos de la cuenca del río Parnaíba son pequeños propietarios, arrendatarios, posseiros, ${ }^{5}$ empleados permanentes y temporales, aparceros dedicados de manera básica al trabajo familiar para su reproducción como campesinos. ${ }^{8}$ La inclusión de los empleados así como de los pequeños propietarios se debe en esencia a la comprobación de la débil diferenciación de los campesinos en la economía rural del área. Su economía de autoconsumo no puede existir desvinculada del mercado, aunque esta vinculación sea "secundaria" para su modo de vida. Su liga con el mercado se da a través de la comercialización de pequeños excedentes, lo que hace que su cultivo de subsistencia, básico para el modo de vida campesino, pueda estar asociado con un producto de mercado; mas en el caso específico aquí tratado, por lo general, al cultivo de subsistencia se liga el alquiler temporal de la fuerza de trabajo para el latifundio, cuyo rendimiento permite suplementar su canasta de consumo. En este sentido, tales campesinos constituyen la reserva de mano de obra del latifundio y conforman el complejo latifundio-minifundio.

Veamos como esa caracterización aparece en el área. La producción comercial de extracción (carnauba, babaçu, tucum, jaborandi) ${ }^{7}$ y la agropecuaria (mamona, ${ }^{8}$ algodón y principalmente ganado bovino), explotadas en los latifundios, toman la mano de obra necesaria, además de unos pocos empleados permanentes (vaqueros, capataces, etc.) de la economía campesina de subsistencia (arrendatarios, socios, pequeños propietarios, unos y otros trabajando algunas veces como jornaleros). Esa economía crea el modo de vida prevaleciente en la Cuenca. Su finalidad primordial es la subsistencia, que se realiza de manera básica a través de la producción para autoconsumo, pero también a través de la venta de sobran-

4 El estudio de esa área agrícolà resulta de una reflexión a partir de datos dispersos: estadísticas genéricas e investigaciones de campo, básicamente entrevistas. De ahí su menor grado de sistematización en relación al estudio de la Cuenca del Parnaiba. Con todo, se piensa que esa disparidad de tratamiento, en esencia, no afecta nuestros objetivos, que se centran en el estudio de las relaciones de producción como principal elemento diferenciador de las formas de organización de la economía rural.

s Campesinos que poseen tierra pero no son propietarios de la misma (N. T.).

- Para una caracterización de las formas de producción rural en el Brasil, entre ellas la "economía campesina", véase el trabajo de Juarez R. B. Lopes, "Desenvolvimento e Estrutura Agraria no Brasil", CEBRAP, mimeografiado. Se utiliza esa caracterización adaptada al caso de la Cuenca.

7 Diferentes tipos de cocoteros: carnauba (palma que produce cera), babaçu, tucum, otros tipos de palmeras típicas brasileñas, igual que el jaborandi que produce aceite (N.T.).

8 Planta de ricino (N. T.). 
tes de productos y de la venta de fuerza de trabajo excedente. La relación con el mercado donde adquieren ciertos instrumentos de trabajo y de manera principal, bienes de consumo básicos, es indispensable al modo de vida campesino.

La economía campesina de subsistencia ${ }^{9}$ que caracteriza a la Cuenca, existe tanto dentro como fuera del latifundio. Cuando se da fuera de él constituye la fracción minifundista (arrendatarios ocupantes y pequeños propietarios) de la capa campesina, con alguna producción directa para el mercado (algodón y algunas hortalizas) y, de manera principal, se realiza un esfuerzo para la obtención de excedentes de productos básicos (arroz, maíz, frijol, yuca, harina) para la comercialización. Con el escaso ingreso monetario - sumado al obtenido por el pago en salario esporádico- compran en el mercado instrumentos y bienes de consumo que no pueden producir y que son indispensables para su modo de vida. Cuando existe dentro del latifundio, constituye la fracción de asociados (vinculados al latifundio, semiasalariados - por lo general disponen de una pequeña huerta y algún ganado menor) de la capa campesina que hace transacciones con algún sobrante de la producción para consumo o recibe algún dinero como jornal y adquiere los medios de vida adicionales que le son indispensables con la venta de propiedades o en los mercados de pequeños núcleos urbanos.

Así, la economía general de la Cuenca, basada en la gran explotación, se configura como un gran complejo latifundio-minifundio cuya dinámica está dada por la economía comercial patrocinadora de una red urbana poco articulada. Los centros urbanos existentes, cuando no son núcleos semirurales de hasta 2000 habitantes (residencia de labradores y sede del artesanado vinculado a la economía campesina) constituyen una red poco integrada, lo que refleja el poco desarrollo de la división social del trabajo. En su mayor parte son centros que viven de la comercialización de los excedentes agrícolas de la economía campesina y sirven, en contrapartida, de canales en la distribución de productos urbanos complementarios de aquella economía.

Algunos centros mayores (sólo nueve ciudades, en 1970, tenían una población superior a 10000 habitantes), resultado histórico de sus funciones comerciales, sirven de apoyo para el beneficio y comercialización de los productos de recolección, de algodón y del ganado.

La redistribución espacial (1950 y 1970) de la población se dio, de manera fundamental, de las áreas rurales hacia las ciudades principales. Aún así, en 1970 tres cuartas partes de la población vivía en el medio rural. Esto pone de manifiesto el gran volumen de trabajo social, bajo

9 Conviene insistir que subsistencia no es sinónimo de autoconsumo; orientada para el mercado, esa economía no dispone de medios que le permitan instaurar un proceso de acumulación de corte capitalista. En ese sentido, la subsistencia es una reproducción de esa economía, de hecho campesina. 
la forma campesina, que la organización de la Cuenca requiere para su mantenimiento y desarrollo.

La disminución de la proporción de la población económicamente activa en el campo (PEA) en el periodo intercensal 1950-1970 fue reducida (de $79 \%$ a $76 \%$ ): la mayor parte del descenso se debe a los cinco municipios con centros urbanos mayores (20000 habitantes). Si excluimos éstos, la baja es de $86 \%$ a $84 \%$ en el decenio 1960-1970.

El carácter rural de la economía y la interpretación de lo rural y urbano se acentúa si se considera que en 1970, el 23\% de la PEA urba. na realizaba actividades primarias (casi 43000 personas, de 187000 ) y $7 \%$ de la PEA rural, actividades secundarias y terciarias $(40000$ de ... 562 000; los cuales constituían un quinto del total de los sectores secundario y terciarios de la Cuenca).

Se hace necesario agregar aquí algunos elementos, por breves que sean, del mundo urbano del área para realzar así su dependencia en relación a "lo rural" y, al mismo tiempo, indicar que con esto se identifica el circuito de la producción social; de este modo se subraya la importancia de los campesinos en la economía del Parnaíba y, por consiguiente, en las exportaciones (principalmente de arroz, maíz, frijol y harina de yuca) para áreas urbanas nordestinas.

De manera sintética, podemos dividir la economía no agropecuaria de extracción de la Cuenca en tres grandes segmentos: aquel en que predominan las unidades con dos o tres empleados o con uso de mano de obra familiar, que podemos denominar el segmento artesanal; otro en que predominan unidades productoras que utilizan cinco, diez o más empleados, que llamaremos el segmento empresarial; y el tercero, patrocinado por el gobierno (municipal, estatal, federal), segmento estatal. ${ }^{10}$

El segmento artesanal que reúne, grosso modo, industria de transformación, comercio de mercaderías, confecciones sobre medida, servicios domésticos remunerados y otros de consumo individual y otras actividades no especificadas, comprende alrededor de 77000 personas de la .PEA urbana $(53 \%)$. El segmento empresarial incluye la industria extractiva mineral, industria de la construcción, servicios de reparación, transportes, comunicaciones y almacenaje, comercio de inmuebles, escuelas y servicios de salud privados y registra 41000 personas (29\% de la PEA urbana). El segmento estatal reúne servicios industriales y servicios de consumo colectivo (excepto el del sector privado) y registra más de 26000 personas $(18 \%)$. En la parte más urbana de la Cuenca, constituida por los nueve municipios con ciudades con más de 10000 habitantes, las proporciones de los tres segmentos permanecen iguales. En una y otra parte, la PEA urbana es ante todo artesanal (más de la mitad), poco menos de

10 Para esta clasificación se utilizó información sobre el tamaño medio de los establecimientos, que constan en los censos económicos de 1960 y 1970 y un análisis global de la organización económica. 
una tercera parte se emplea en el pequeño sector empresarial, y casi un quinto $(18 \%)$ depende del sector estatal.

El empleo, en el sector artesanal de la economía, depende del aumento de las necesidades inmediatas de consumo de la población total; crece "horizontalmente", por el aumento de ésta (dada la incapacidad de la unidad familiar campesina y no campesina de proveerse integralmente de todo lo necesario), multiplicado por su poder adquisitivo. Por otro lado, depende de la expansión del segmento empresarial que, a su vez, depende de las ventas externas de la Cuenca y del segmento estatal. La demanda de bienes artesanales parece aumentar ante la supuesta redistribución espacial de la población, de manera principal en la dirección campo-ciudad, sumada a su bajo poder adquisitivo. La diferenciación entre los segmentos industrial-empresarial parece ampliarse cuando es fomentada por el gobierno (como en el caso de la industria de la construcción) y genera entonces oportunidades de empleo. Queda así el gran patrocinador de la "renovación económica" y el gran empresario en los sectores de servicios no autónomos, que es el Estado. Es en el sector estatal donde la población busca oportunidades de empleo para obtener ingresos; y como son reducidas, se incentiva aún más al sector artesanal.

De esa manera, es en el contexto de la economía del área, en la que el $85 \%$ de la fuerza de trabajo (excluidos los nueve municipios más urbanos) se dedica a actividades primarias y en donde parte de las actividades secundarias y terciarias son adjuntas de una misma economía rural, como debemos entender el modo de vida prevaleciente, una economía campesina de subsistencia. Sobre esta economía reposa aquélla dirigida de manera directa hacia la comercialización y la que configura la estructura socioeconómica de la Cuenca bajo la forma de un complejo latifundio-minifundio. ${ }^{11}$

La organización económica del campo muestra la historia de sus últimos cien años. La demanda de pieles, cueros y de manera principal de ganado, originaria de los varios mercados locales y de áreas nordestinas así como la demanda internacional de productos de extracción (como cera de carnauba, babaçu y jaborandi) propició la formación de una economía comercial de amplia base campesina. A grandes rasgos, los elementos de la organización económica rural del área son: ganadería y extracción, grandes propiedades y marcado ausentismo de los dueños de la tierra, aumento continuo de la economía campesina (interna y externa a las grandes propiedades) y débil desarrollo de la capa de propietarios pequeños y medianos, cuyo modo de vida no difiere en rigor de la gran mayoría campesina.

El desarrollo de esa organización económica rural, como se vio, se

11 Como veremos, al tratar el tamaño de los establecimientos, existe un número significativo de ellos que podría hacer pensar en un segmento de pequeñas y medianas propiedades; de hecho, no se tiene, por necesidad, una capa social diferenciada de la masa campesina, dada la naturaleza de la economía del área. 
refleja y tiene continuidad en el crecimiento urbano, en especial en los grandes centros (es evidente que ahí bajo la forma de segmento artesanal). Se debe recalcar que aún en el presente, el campo atrae el crecimiento de las ciudades. Un ejemplo tal vez extremo de esa dependencia, se encuentra en la ciudad de Picos, una de las nueve mayores de la Cuenca: "Es durante las zafras (julio y diciembre) cuando se amplían las perspectivas de trabajo en el campo, dada la necesidad de mano de obra para la cosecha. Esto auspicia la migración de parte de la población que vive en los barrios periféricos de la ciudad de Picos. De origen rural, se mantiene como población agrícola marginal a la vida urbana y en la época de cosecha de algodón se dirige a diversos lugares del valle. También de áreas rurales del centro este piauiense, del Baixao de Guaribas y de Itaim (áreas de minifundios: establecimientos de hasta 10 hectáreas) sale el elemento humano en busca de zonas en donde se realiza el cultivo de algodón. Consideran la zafra como una posibilidad de trabajo con qué complementar su pobre dieta anual... Toda la vida urbana depende de las zafras; sea en el mercado comercial, sea en las industrias nacientes de Picos, se amplía la oferta de empleo en esta época". ${ }^{12}$

La redistribución espacial y ocupacional de la población en la Cuenca en los últimos 20 años, como vimos, básicamente no afectó la estructura de organización económico-social y, por lo tanto, ni la del campo. En este contexto, hay una relación especial entre población, trabajo agrario y apropiación de la tierra. Producción comercial y economía de subsistencia conforman un organismo que absorbe y neutraliza las oscilaciones del mercado sin afectar la estructura agraria.

Ocurre una regulación entre tierra y población rural a tavés de tres procesos: el primero, vinculado a la historia de la Cuenca, relativo a la apropiación de la tierra de manera monopólica bajo la forma de grandes áreas cuya finalidad principal era la de atender las demandas externas; ${ }^{13}$

12 Picos e Sua Região, Subsidios ao Planejamento da Area Nordestina, Rio de Janeiro, 1971, pp. 25-26. En el trabajo de la Secretaría de Planeación del Gobierno de Piauí, Estudos e Pesquisas da Micro-Região I e das Areas das Regiões do Buriti e do Cajueiro (MR 45), 1972, 3 vols., registra que $11.3 \%$ de los jefes de familia residentes en zona urbana son labradores: así, "gran parte de las familias de las pequeñas ciudades viven en función de la tierra, como también de las zonas utrbanas".

13 La historia contribuye en mucho al entendimiento de la organización económica rural del área. "La vida agrícola, surgida como subsidiaria y complementaria de la hacienda ganadera en los siglos XVIII y xIx, creció lentamente... Interesando más a vaqueros y agregados y menos a los hacendados propietarios, cuyos intereses eran el ganado, la agricultura se restringía al consumo de la hacienda y de los pequeños conglomerados que iban surgiendo en el interior. La diversificación de la economía de subsistencia para los propios mercados locales se inició en el siglo xIX con la ocupación de los pantanos más insalubres por parte de los primeros labradores, derivados de los excesos de población de la hacienda y por poblaciones cearences afectadas por las sequías ... En la gran propiedad el interés del hacendado ausentista es el ganado (en la actualidad), y de los que no 
propició la formación de una pequeña capa social de indiscutible dominio del área y ligada al, o canalizadora del poder del estado, lo que reforzó su monopolio, posibilitando su extensión; el segundo, ligado a los requerimientos de mano de obra del latifundio para las actividades comerciales, al mismo tiempo que la provisión de esa mano de obra y de sus familiares, tanto dentro como fuera de la gran explotación y, el tercero, relacionado a los movimientos poblacionales de la masa campesina según la relación entre tierra disponible para cultivos de subsistencia y el crecimiento de dicha masa; ${ }^{14}$ la región de la Cuenca del Parnaíba, según el equipo de estudios demográficos del CEBRAP, se caracterizó en los últimos decenios como un área de emigración. En la actualidad, la tendencia parece ser de mayor retención de la población, en especial en las áreas cearenses y piauienses de la Cuenca. Entre 1960 y 1970 el área de Maranhao registró un fuerte rechazo de población, en correspondencia con la emigración, posiblemente de cerca del $68 \%$ de su crecimiento vegetativo. La parte de la Cuenca perteneciente a Ceará continuó con un saldo migratorio negativo, pero en menor grado que en el decenio anterior (emigró $18.5 \%$ de su crecimiento vegetativo). El Piauí, en este último decenio, parece no haber sufrido emigraciones relevantes y como consecuencia del pequeño flujo de inmigrantes resultó con un saldo migratorio positivo; ${ }^{15}$ esta alteración del flujo de emigrantes debe ser considerada a la luz de dos elementos: a) la disminución de la demanda de productos extractivos (mercado mundial) concomitante con la urbanización de los centros mayores y al alquiler, por productos, de áreas diminutas de los latifundios (arrendamientos); $b$ ) acciones estatales en el área (plantas hidroeléctricas, carreteras, colonias de agricultores) que generaron oportunidades de empleo.

Se intenta ahora detallar un poco más los elementos de la producción comercial y de la economía de subsistencia, así como también sus relaciones.

En la explotación agropecuaria y extractiva, la fuerza de trabajo empleada en la producción comercial propiamente dicha (algodón, ganadería, frutas y semillas oleaginosas y ceras) sumaba en 1970 cerca de 72000

tienen tierra, la agricultura de subsistencia. Esta crece con el propio incremento poblacional...", Teresina e Seu Espaço Regional (Subsidios ao Planejamento da Area Nordestina), IBGE, 1971, Rio de Janeiro, pp. 27 y 32 (subrayados del autor).

14 En cuanto a los factores de expulsión que originan migraciones, Paulo Singer considera dos clases: los factores de cambio y los de estancamiento: los primeros son consecuencia de la introducción de relaciones capitalistas de producción en el campo (es el caso de Assis, como veremos), al paso que los factores de estancamiento, de una creciente presión poblacional sobre la disponibilidad de áreas cultivables que sufren limitaciones o de insuficiencia física de tierra aprovechable o de la monopolización de buena parte de ellas por los grandes propietarios - sin cambio del sistema productivo. Véase Paulo Singer, "Migrações Internas: Considerações Teóricas sobre seu Estudo", en Economia Politica da Urbanização, São Paulo, Ediciones CEBRAP, 1973.

15 Projeção da População da Bacia do Parnaíbe, CEBrap, 1974, pp. 20-26. 
personas, al paso que a la economía de su'sistencia (arroz, otros cultivos, caña de azúcar, caza y pesca) correspondían $492000(87 \%$ del total del sector); de este último total, cerca de 40000 residían en el área urbana.

El examen de la distribución del personal ocupado en el sector primario, según la posición en la ocupación, confirma el doble carácter de la estructura agraria: las relaciones más próximas a las capitalistas ${ }^{16}$ son las de empleado ( $11 \%$ del sector) y empleados $(0.6 \%)$; el restante $88 \%$ está constituido por trabajadores por cuenta propia (propietarios, arrendatarios, ocupantes: casi $50 \%)$, aparceros $(18 \%)$ y sus familiares no remunerados $(21 \%)$, o sea el estrato campesino (datos de 1970$)$. La estructura agrícola ya señala parte de esta dicotomía: $14 \%$ de los predios rurales (128000 en 1972) poseían hasta cinco hectáreas y ocupaban apenas $0.3 \%$ del área total, y $5 \%$ poseían 500 hectáreas o más y ocupaban mucho más de la mitad del área. Mientras tanto, como ya se indicó, la capa campesina existe también dentro de la gran propiedad, bajo la forma de aparceros, arrendatarios y agregados.

No se dispone de estadísticas apropiadas para componer un cuadro evolutivo de la estructura y la composición de las diversas capas sociales del campo. No obstante, con bastante trabajo, con los datos disponibles y toda una serie de adaptaciones y estimaciones se llegó a las cifras del cuadro 1 que permite avanzar en la comprensión de la estructura rural y su evolución.

Para una mejor comprensión de las categorías del personal ocupado y su agrupación en latifundistas y campesinos (personal ocupado dentro y fuera de los latifundios) conviene dar algunos elementos sobre los rendimientos monetarios, ya que éstos expresan la cantidad y la diversidad de las relaciones sociales normadas por el mercado y la capacidad de unos grupos para negociar con ventaja en relación a otros.

De los 562000 habitantes que forman el PEA rural de la Cuenca, 119000 no reciben ninguna remuneración. De los remunerados, la gran mayoría son autónomos (448 921); casi 12\%, 66000 , son empleados y grandes propietarios (todas son categorías del censo demográfico). $29 \%$ de los empleadores (987) del sector, $86 \%$ de los propietarios autónomos y $93 \%$ de los empleados recibían, en 1970 , hasta 100 cruceiros. $^{17}$ Esto quiere decir que los empleados, por un lado, y los arrendatarios, ocupantess y propietarios autónomos, por el otro (se puede agregar buena parte

16 Lo que no quiere decir que sean de hecho relaciones de producción capitalistas puras; con gran frecuencia el empleado permanente en la cuenca (para no tocar por ahora a los temporales) se relaciona al trabajador en la ganadería que, además del salario monetario, recibe la cuarta (o sea, una de cada cuatro crías) y posee un rocado. El censo demográfico de 1970 define como "empleados" a "los que trabajan mediante remuneración en dinero, especie o utilidades".

17 Cien cruzeiros representaban $80 \%$ del salario mínimo regional. Véase Anuário Estatístico do Brasil, IBGE, 1973, p. 641. Se trata del salario mínimo en Teresina $(\mathrm{Cr} \$ 124.80=25$ dólares $)$. 


\section{Cuadro 1}

Cuenca del Río Paranaíba: Distribución de las categorías del personal EN ACTIVIDADES AGROPECUARIAS Y DE EXTRACCIÓN, 1950, 1960, 1970

(porcientos)

\begin{tabular}{|c|c|c|c|}
\hline & 1950 & 1960 & 1970 \\
\hline Total (males) & 331.4 & 610.2 & 1063.0 \\
\hline Eatifundistas (empleadores) & $\underline{2.1}$ & 1.2 & $\underline{0.6}$ \\
\hline Personal ocupado "en" los latifundios & 48.6 & 33.3 & $\underline{2} 4 . \underline{8}$ \\
\hline $\begin{array}{c}\text { Eoploados (perwaneates más terpo- } \\
\text { rales) }\end{array}$ & 37.2 & 27.9 & - \\
\hline $\begin{array}{c}\text { Otra condedón (aparceros y otras } \\
\text { condiciones) }\end{array}$ & 11.4 & 6.4 & - \\
\hline $\begin{array}{l}\text { Personal ocupado "fuera" de los lati-- } \\
\text { fundios }\end{array}$ & 49.3 & $\underline{64.5}$ & 14.6 \\
\hline Propietarics autóncanes & 10.8 & 9.5 & 9.8 \\
\hline Arrendatarios & 0.6 & 7.3 & 11.9 \\
\hline Ocupantes & 0.9 & 1.8 & 8.2 \\
\hline Administradores & 2.2 & 1.7 & 44.7 \\
\hline Familiares no remunerados & 34.8 & 44.2 & \\
\hline
\end{tabular}

Fuente: Censos Agrícolas y Demográficos, 1950, 1960 y 1970.

a Administradores en establecimientos sin empleados.

de los empleadores) no se diferencian por el ingreso monetario. ${ }^{18}$ No son los productos de las relaciones mercantiles de trabajo los que organizan a los grupos sociales rurales (excepto, es claro, a los latifundistas) pero, la pequeña suma monetaria es expresión de esas relaciones.

Los rendimientos son expresión del empleo en el campo y éste de las relaciones de producción en el contexto de las fuerzas productivas de la Cuenca.

En un estudio sobre el área de Picos, con 70000 habitantes, región que registra la mayor producción agrícola de la Cuenca, hay una tentativa de cálculo de la participación de las diversas categorías profesionales de la población: $34 \%$ son minifundistas (propietarios de superficies menores de 10 hectáreas); $30 \%$ son trabajadores temporales y $18 \%$, pequeños propietarios (poseen entre 10 y 100 hectáreas). Las demás categorías cuentan poco. Si las tres categorías se distinguen, según la manera de ver del analista, por sus niveles de vida - los trabajadores temporales serían

18 Es evidente que se trata de medianos y pequeños propietarios. Los grandes que denominamos latifundistas, monopolizadores del ingreso monetario, son por completo diferentes de la masa campesina. Consúltese el cuadro 4 donde aparecen grandes propietarios hasta en propiedades minúsculas. 
miserables, los minifundistas, pobres y los pequeños propietarios apenas tendrían nivel satisfactorio - las categorías de trabajadores temporales y minifundistas, que suman $45000(64 \%)$ se asemejan en cierto modo en cuanto a la temporalidad de su trabajo. Si durante el tiempo que media entre cada zafra, afirma el autor del citado estudio, la población rural es de 50000 , durante la zafra (julio a diciembre) alcanza 150000 . "No es de sorprender, por consiguiente, que esa población rural sea inestable. Ante la noticia más vaga emigran en busca de una riqueza, la mayoría de las veces, ficticia."

El cuadro 1 debe ser entendido en ese panorama económico (en realidad, resultó de esos análisis) y no en el "funcionamiento" de esa economía. La distinción misma en las capas campesinas, entre aquellos dentro de los latifundios y los de fuera de ellos se muestra, hasta cierto punto, ambigua, cuando consideramos su dinámica económica.

La disminución relativa de los latifundios y el aumento consecuente de las capas campesinas viene a confirmar la hipótesis de la apropiación previa de las mejores tierras por las grandes explotaciones; en realidad, el número de parcelas de 500 hectáreas y más, así como su superficie, han permanecido relativamente estables en el último decenio (1960-1970); por otro lado, con el crecimiento campesino, se registró una presión aguda sobre la tierra, sea por el aumento de los arrendamientos minúsculos, sea por la ocupación de las tierras de calidad más baja y más distante de los mercados urbanos. Las formas que adopta la multiplicación de la capa campesina son el arrendamiento y la ocupación, como respuestas al aumento poblacional, ${ }^{19}$ que se expande en estrecha vinculación con las actividades mercantiles (urbanas), las cuales le dan la oportunidad de obtener el suplemento monetario indispensable a su modo de vida; de esa forma, en las regiones en donde se localizan los grandes centros urbanos, son más numerosos los arrendatarios (cuyo pago es el ingresoproducto). Como son tierras apropiadas, su crecimiento no ocurrió a expensas del latifundio sino dentro de él. ${ }^{20}$

19 Se considera que el crecimiento de la población con dificultad puede entenderse - como parece sugerir el texto- como motor de los incrementos de arrendatarios y de lo que esto trae consigo. La presión sobre la tierra se relaciona más con la pauperización absoluta y relativa de las clases campesinas y fuerza el aumento de transferencia de valor puro a los medios urbanos (explotación) vinculado al monopolio de la tierra y al desarrollo económico a nivel nacional. En tal contexto, la reproducción de las condiciones de vida de las clases campesinas depende de más trabajo (es obvio que la afirmación carece de los momentos mediadores entre los dos términos, aspecto que escapa a un trabajo de esta naturaleza).

20 Francisco Sá en su magnífico trabajo "O Desenvolvimento da Agricultura Nordestina e a Função das Atividades de Subsistencia”, Estudos cEBRAP 3, Ediciones CEBRAP, 1973, ya señala ese proceso en curso: "En verdad la expansión de los minifundios se viene haciendo de manera principal en la forma de pequeños establecimientos arrendados dentro de propiedades mayores. Estos pequeños arrendamientos han crecido más que las pequeñas propiedades explotadas en forma directa por los propietarios. Este fenómeno (el aumento de los establecimientos 
En el cuadro 1 ese proceso puede "leerse" de la siguiente manera: el personal ocupado en los latifundios es "sustituido", gracias al crecimiento poblacional de la capa campesina que presiona así sobre la tierra, de manera principal los arrendatarios. La estructura productiva latifundista (de extracción, algodón y ganado) al necesitar de extensas tierras ya no soporta aquel volumen poblacional y, al mismo tiempo que no intensifica los métodos de explotación, exige mano de obra temporal; lo que lleva a la hipótesis de un reforzamiento del complejo latifundio-minifundio $\mathrm{y}$, en consecuencia, de las capas campesinas. Se podría decir que, si en su origen el latifundio generó y sustentó el minifundio, ahora éste asegura la existencia del latifundio.

Cabe señalar, para aclarar posibles dudas, que los empleados temporales y permanentes, o de otro carácter (agregados, moradores), en las condiciones de la Cuenca, constituyen también una fracción del estrato campesino, personal con huertas de subsistencia propia, sometidos a obligaciones con el dueño de la propiedad y sus representantes (administrador, capataz). Los empleados temporales son con frecuencia propietarios o arrendatarios autónomos, o aun agregados, de la misma hacienda o de otras que suplementan su producción para autoconsumo con el ingreso periódico de su fuerza de trabajo.

No hay duda que ese campesinado difiere del campesinado de economía natural, pues cualquier ingreso monetario suplementario, aunque pequeño, les es esencial. Lo que pensamos es que tal clase no muestra diferencia en sus capas al grado de constituirse en clases para el capital. No hay duda en cuanto a su subordinación al capital usurario y comercial concentrados en manos oligopsónicas, básicamente de los latifundistas, y lo mismo resulta desde el punto de vista del proceso global de desarrollo económico, subordinado al capital industrial y financiero. Pero ese mismo capital no destruyó ni pudo suprimir la economía campesina.

Exactamente aquí nos encontramos con la subordinación formal del trabajo campesino al capital. Este prácticamente dejó intacta la esfera productiva agrícola pues, por ahora, bastan los mecanismos de coacción económica, ${ }^{21}$ de los cuales forma parte la dominación tradicional para

arrendados), se mostró intenso en particular en los Estados de población más reciente, o sea, en Maranhao y en Piauí. En estas dos unidades de la Federación había, en 1950, apenas 5305 establecimientos arrendados de menos de cinco hectáreas, que ocupaban 9534 hectáreas. En 1960 su número se elevó hasta 107186 con 186406 hectáreas. En contraste, el aumento de los pequeños establecimientos propios fue mínimo. En cuanto a los establecimientos "ocupados", o sea, ni propios ni arrendados pero dentro del grupo de menos de cinco hectáreas, registran un importante crecimiento, aunque muy inferior al de las tierras arrendadas, tanto en términos absolutos como relativos". Y concluye: "La agricultura campesina, o sea la de los pequeños propietarios y arrendatarios, dedicados en gran parte a producir para su propio consumo, no parece, por tanto, dar muestras de que sea superada por la agricultura comercial, aunque ésta se encuentre también en expansión".

21 Necesidad de mano de obra por parte del latifundio, el "antiguo ejército rural de reserva", del que habla Juarez R. B. Lopes, en "Desenvolvimento e Estrutura 
que el capital se apropie del "sobretrabajo" en la esfera de la circulación $y$, de esa manera, el producto campesino aparezca en la canasta de consumo de la fuerza de trabajo urbana. Esa falta de penetración en la esfera productiva es importante ya que la oferta de alimentos que es, de manera básica, la suma de numerosos pequeños excedentes, no recibe el influjo de los precios de los alimentos en ascenso (real) en el medio urbano (no sólo en los grandes núcleos de la Cuenca, sino en los del área nordestina abarcada por la oferta) por el papel desempeñado por los escasos compradores. De esa forma, la oferta agrícola se muestra "insensible" al comportamiento del mercado (lo que no ocurre con la producción comercial de los latifundios, en donde las oscilaciones del mercado se transfieren a la economía campesina), dado que el aumento de la producción se relaciona al aumento de la masa campesina que trabaja en la agricultura de subsistencia. ${ }^{22}$

Por consiguiente, no hay aplicación de capital en la agricultura si bien se dio un aumento del producto agrícola. Al no haber incentivos, vía precios, no surgió en la Cuenca una agricultura comercial capitalista de alimentos.

No hubo aquí, como se vio, expropiación de propiedades campesinas; no hubo acumulación previa de capital en la agricultura, pero hubo y hay expropiación del excedente que se conecta al desarrollo económico del país, vía la circulación. Podemos afirmar que estamos frente a una acumulación primitiva de capital en el interior del proceso global de reproducción ampliada. ${ }^{23}$

Este proceso aparece en el grupo opuesto del campesinado, los latifundistas, a través de la expropiación del excedente y su transferencia al medio urbano -industrial-financiero.

Relacionemos los dos tipos de producción (comercial y de economía de subsistencia) con varias categorías de la fuerza de trabajo agrícola y con los tamaños de los establecimientos. Al no haberse publicado los resultados del Censo Agrícola de 1970, estamos obligados a utilizar los de

Agrária no Brasil”, sistema de deudas, de condiciones, etc. Por otro lado, en términos de la dinámica de la población y el aumento del "antiguo ejército rural de reserva", se nota que ya se hace sentir la caída de las tasas de mortalidad, lo que evidencia el papel del Estado, agente "moderno" que colabora con la agricultura "atrasada"; el número de hijos tenidos por mujer se mantiene constante, 3.63. Se debe registrar también que los estıldios del Equipo de Demografía (antes citados) constataron que el crecimiento vegetativo (porcentual) de la Cuenca (30.76) es menor que el brasileño (32.92) y mucho menor que el del Nordeste (41.02).

22 Véase Francisco Sá Jr., loc. cit. y Juarez R. B. Lopes, "Desenvolvimento e Migrações: Uma Abordagem Histórico-Estrutural", Estudos CEBRAP 6, octubre-diciembre de 1973.

23 "...la acumulación primitiva no se da sola en la génesis del capitalismo bajo ciertas condiciones específicas, de manera principal cuando ese capitalismo crece por creación de periferias, la acumulación primitiva es estructural y no sólo genética", Francisco de Oliveira, "A Economia Brasileira. Crítica à Razão Dualista", Estudos CEBRAP 2, p. 16. 
1960. Para las relaciones que se desean, las estadísticas disponibles de 1960 sólo permiten observaciones a nivel de entidad. De este modo, por tratarse de datos sobre la estructura agrícola, en sus líneas generales, y en vista de que Piauí se incluye integralmente en la Cuenca y por constituir la parte mayor, las consideraciones que se siguen pueden servir como una aproximación de la Cuenca.

En el cuadro 2 se distribuyen los establecimientos y sus áreas, según la actividad predominante, por clases de áreas y se clasifica la actividad en "comercial" (algodón, babaçu, carnauba, bovinos) y de "subsistencia" (arroz, maíz, frijol, caña y porcinos).

Cuadro 2

Piauí: Distribución de los establecimientos Y SUPerficies POR TAMAÑos SEGÚN LA ACTIVIDAD PREDOMINANTE, 1960 (porcientos) $^{\mathrm{a}}$

\begin{tabular}{|c|c|c|c|c|c|c|c|c|}
\hline \multirow{2}{*}{$\begin{array}{c}\text { Actividad } \\
\text { predominanto }\end{array}$} & \multicolumn{2}{|c|}{$\begin{array}{c}\text { K.ss de } \\
500 \text { hectáreas }\end{array}$} & \multicolumn{2}{|c|}{$\begin{array}{c}100-500 \\
\text { bectareas }\end{array}$} & \multicolumn{2}{|c|}{$\begin{array}{c}5-100 \\
\text { bectáreas }\end{array}$} & \multicolumn{2}{|c|}{$\begin{array}{r}\text { hasta } 5 \\
\text { heotáreas }\end{array}$} \\
\hline & $\mathrm{E}^{\mathrm{b} /}$ & s & $E$ & $\varepsilon$ & $E$ & $\mathbf{s}$ & $\mathbf{E}$ & $s$ \\
\hline Subsiatencza & 25 & 20 & 47 & 44 & 70 & 65 & 93 & 91 \\
\hline Comercial & 67 & 70 & 45 & 47 & 23 & 27 & 15 & 6 \\
\hline
\end{tabular}

Fuente: Censo agrícola, 1960.

a Lo que falta en las columnas para $100 \%$, corresponde a otras actividades, además de las enumeradas en el texto.

b E: establecimiento; S: superficie.

La producción comercial como actividad predominante tiende a darse en los establecimientos de áreas mayores, mientras la producción de subsistencia en los menores. Es imposible trazar una línea clara de separación entre los diversos tamaños de área y tipos de economía.

En la estructura productiva de los establecimientos de la clase de $\mathbf{5 0 0}$ y más hectáreas, ${ }^{24}$ aquéllos que tienen ganado y carnauba como actividades predominantes, suman $64 \%$ del área; prácticamente toda el área de las unidades agropecuarias donde prevalece la producción comercial. En las unidades de la clase siguiente, 100-500 hectáreas, ganado y carnauba alcanzan $40 \%$ de su superficie. En la clase de 5-100 hectáreas, encontramos establecimientos con esa estructura productiva que suman apenas $20 \%$ de la superficie. Si se considera que ganado bovino, babaçu y carnauba forman parte de la explotación latifundista se puede inferir del cuadro 2 que, por una parte, ésta no se conceptúa simplemente por el

24 El examen preliminar de los datos llevó a no considerar como establecimientos grandes a los de 1000 y más hectáreas, dado que en su estructura productiva eran muy semejantes a los de 500 hectáreas y, además de esto, se distanciaban bastante del grupo de 100 a 500. 
tamaño ${ }^{25} \mathrm{y}$, por otra, que aquellos productos se adentran bien a fondo en los establecimientos de tamaño "medio". Es en los establecimientos de hasta cinco hectáreas donde el latifundio encuentra su "límite".

La economía de subsistencia como actividad predominante, si se consideran los tipos de superficies a partir de los establecimientos mayores, tiene lugar una trayectoria inversa a la de la economía comercial (véase el cuadro 2). Esta es prácticamente exclusiva de los minifundios (establecimientos de hasta cinco hectáreas; en los mayores más de 500 hectáreas), alcanza la cuarta parte de los establecimientos, con $20 \%$ de su área. Así, la subsistencia está presente en todas las clases de áreas, lo que viene a reafirmar la uniformidad de la Cuenca en cuanto a la presencia campesina. Algunos productos de subsistencia (arroz por ejemplo), en las clases mayores pueden ser producidos en gran escala, gracias a la irrigación (posible gra¿ias a la construcción de canales costeados por el gobierno federal); mas, todo lleva a creer que se trata de la excepción. En la realidad, la economía de subsistencia proviene de pequeñisimas explotaciones dentro de la gran propiedad que utiliza el mismo proceso y las técnicas del minifundio, "fuera" de la gran propiedad. En aquéllas, la subsistencia es producida por agregados que pagan, como renta de la tierra, una o dos cuartas (33 a 66 kilos), de determinadas producciones, por tarea de tierra. ${ }^{26}$

En cuanto a la producción de bienes alimenticios, latifundio y minifundio casi no se diferencian; en ambos predomina la pequeña explotación agrícola. En el gran establecimiento coexiste, así, al lado de las producciones comerciales, con por lo menos cierta unidad de dirección, multiplicidad de pequeños lotes de tierra, explotados por familias campesinas, donde se canalizan los excedentes, vía renta de la tierra o la venta directa, por el agregado, de los reducidos excedentes de su autoconsumo, en los mercados locales de la Cuenca o en los otros mercados nordestinos.

El examen del cuadro 3, con la distribución porcentual de los establecimientos según su tamaño, por las extensiones de áreas cultivadas que se poseen (Piauí, 1960) ofrece elementos adicionales para la comprensión de la organización productiva latifundista en su vinculación con la economía campesina.

Cabe señalar las elevadas proporciones de establecimientos con pequeñas áreas cultivadas (hasta cinco hectáreas), hasta en los de tamaño mayor: casi una tercera parte en los de más de 500 hectáreas; en éstos, aún cerca

25 A propósito, vale la pena reforzar la idea según la cual el latifundio no se conceptúa, de manera simplista, por el elemento gran extensión de tierra. En Teresina e Seu Espaço Regional (p. 32), hay una aguda observación en ese sentido: "Gran propiedad (caracterizada como latifundio, cuyas áreas varían de 400 a 500 hectáreas o, en ciertos casos, de 1000,5000 o hasta 10000 hectáreas, en áreas próximas de Teresina) ...".

26 Datos obtenidos de entrevistas realizadas por Fernando $H$. Cardoso, Juarez R. B. Lopes y Renée Germano, en varios lugares de Piauí, durante el mes de marzo de 1974. 


\section{Cuadro 3}

Piauí: Distribución DE ESTABlecimientos SEgún tAMAÑo, POR LA EXTENSIÓN DEL ÁREA CULTIVADA, 1960

(porcientos)

\begin{tabular}{|c|c|c|c|c|c|}
\hline \multirow{2}{*}{$\begin{array}{l}\text { Extensión del } \\
\text { ároa cuitzvada } \\
\text { (nectáreas) }\end{array}$} & \multicolumn{5}{|c|}{$\begin{array}{c}\text { Establectmientos segin tamaño } \\
\text { (hectareas) }\end{array}$} \\
\hline & Más de 500 & & 100 a 500 & 5 a 100 & Hasta 5 \\
\hline Hasta 5 & 32 & & 41 & 54 & 100 \\
\hline De 5 a 50 & 57 & “ & 55 & 45 & - \\
\hline De 50 y más & 11 & & 4 & & - \\
\hline
\end{tabular}

Fuente: Censo Agrícola, 1960.

a Estos totales constituyen $75,86,92$ y $98 \%$ respectivamente, de los establecimientos en cuatro tamaños de área (de mayor o menor). El censo se aclara si los establecimientos omitidos no tienen superficies cultivadas (hipótesis más factible, desde nuestro punto de vista) o si no proporcionaron la información.

del $90 \%$ de los establecimientos tiene menos de 50 hectáreas de área cultivada. Estas cifras son coherentes con la conclusión referente a la permanencia de la economía de subsistencia dentro del latifundio. Apenas $11 \%$ de los establecimientos de esta clase registra áreas cultivadas superiores a 50 hectáreas, lo que permite, en esos casos, pensar en mayores excedentes de la producción de subsistencia para el mercado (aunque hay probabilidad de que esas mayores áreas cultivadas estén todas subdivididas para el trabajo, por numerosas familias de agregados).

Analicemos el cuadro 4, aun cuando con datos para Piauí de 1960, donde se relaciona la fuerza de trabajo agropecuaria con los tamaños de área de los establecimientos. ${ }^{27}$

Surge de inmediato la gran capa de campesinos (casi 2/3); no sólo numerosos sino que están en todas las clases del área, lo que señala la uniformidad de la Cuenca. En verdad, la economía campesina ocurre dentro y fuera del latifundio, es decir, engloba además de campesinos "autónomos" parte del personal ocupado en los latifundios.

27 Para la distinción de los responsables de los establecimientos (propietarios, administradores, arrendatarios y ocupantes) en "Latifundistas (empleadores)" y "autonomos" (de varios tipos) se procedió como sigue: fueron considerados "latifundistas", números iguales, en cada estrato de área, a los establecimientos con empleados; estas cantidades fueron después deducidas de las varias categorías de responsables, de manera proporcional a los de sus contingentes. Está claro que la estimación de "latifundistas" exagera bastante la categoría, toda vez que para ser incluido en ella era suficiente tener empleados permanentes o temporales. Si se tiene en cuenta esta sobrestimación se refuerzan aún más las conclusiones sobre el volumen de la capa campesina en todas las clases de áreas. Véase el cuadro 1, donde los cálculos y las estimaciones procuran con mayor precisión la participación de los varios estratos de la sociedad rural. Por ejemplo, en 1970, en toda la cuenca había 3414 empleadores en el sector primario o sea $0.6 \%$ del PEA del sector. 
Cuadro 4

Piauf: Distribución de las categorf́as de personal ocupado EN EL SECTOR AGROPECUARIO POR CLASES DE TAMAÑO

\begin{tabular}{|c|c|c|c|c|c|}
\hline \multirow{2}{*}{$\begin{array}{l}\text { Categoria del } \\
\text { perscnal ocupado } \\
\text { - }\end{array}$} & \multicolumn{5}{|c|}{ Clazes de tanaño (sectíreas) } \\
\hline & Total & $\begin{array}{l}\text { Hás de } \\
500\end{array}$ & $\begin{array}{c}100 a \\
500\end{array}$ & 5 a 100 & Hasta 5 \\
\hline Letifundistas (enpleadores) & $\underline{6.3}$ & 7.1 & 7.3 & $\underline{6.6}$ & 4.6 \\
\hline $\begin{array}{l}\text { Personal ocupado "en" los } \\
\text { latifundios }\end{array}$ & 21.0 & 62.3 & 43.7 & $\underline{31.0}$ & 14.7 \\
\hline Enpleados permanentes & 2.6 & 7.6 & $4 \cdot 3$ & 2.0 & 1.0 \\
\hline mpleados temporales & 23.3 & 35.6 & 30.2 & $24.0^{\circ}$ & 11.7 \\
\hline Aparceros & 2.4 & 5.9 & 3.8 & 2.2 & 0.6 \\
\hline Otra condicien & 3.5 & 13.2 & 5.4 & 2.2 & 1.4 \\
\hline $\begin{array}{l}\text { Personal ocupado "fuera" de } \\
\text { los latifunáios } \\
\text { Autónomos" }\end{array}$ & 61.9 & $\underline{30.6}$ & 42.0 & 62.4 & 80.7 \\
\hline Propietarios & 9.1 & 3.8 & 8.3 & 13.1 & 3.8 \\
\hline Arrendatarios & 6.9 & 0.3 & 0.4 & 1.8 & 23.5 \\
\hline Ocupartes & 1.0 & 0.0 & 0.1 & 1.0 & 2.2 \\
\hline Administradores & 1.1 & 2.2 & 1.9 & 1.0 & 0.3 \\
\hline $\begin{array}{l}\text { Yamiliares no remunera- } \\
\text { cos }\end{array}$ & 43.8 & 24.3 & 30.3 & 45.5 & 50.9 \\
\hline Total (willares) & 358.3 & $\underline{27.2}$ & 72.2 & $15 y .3$ & 20.7 \\
\hline
\end{tabular}

Fuente: Censo agrícola, 1960.

a Estimados, véase la nota 27 del texto.

b Agregados, moradores, etc.

c Administradores en establecimientos sin empleados.

Observemos la cuestión desde otro ángulo, esto es, en donde las relaciones de producción capitalistas puras tienen mayores probabilidades de existir. La relación propietario-latifundista-empleado permanente, es el único indicador disponible capaz de señalar relaciones de producción de esa especie. Si consideramos que en las condiciones de la Cuenca, el empleo permanente con frecuencia tiende a vincularse a las actividades pecuarias, se puede concluir que son relaciones, a lo máximo, semicapitalistas ya que la calidad de asalariado, como tal, no regula ni conforma la reproducción de los trabajadores permanentes; de ahí la cuarta, de ahí la huerta (véase la nota 16). Por eso se puede afirmar con certeza que el elevado peso de los trabajadores permanentes en los predios mayores de 100 hectáreas (proporción superior al $4 \%$ ) indica la importancia del grupo en la estructura productiva de esos establecimientos y en su estructura ocupacional.

La gran mayoría de los campesinos autónomos son propietarios y arrendatarios; ambas categorías, en todo semejantes (fuera del pago de la renta de la tierra por los últimos), trabajan sus pequeñas explotacio- 
nes, propias o alquiladas, auxiliados por sus familiares, ${ }^{28}$ sólo en raras ocasiones emplean alguna mano de obra eventual. Por el contrario, con mayor frecuencia deben emplearse en los latifundios y alternar el trabajo en su tierra con la labor en la gran propiedad. De hecho, los empleados temporales (casi la cuarta parte de la fuerza de trabajo; la mayoría de los ocupados en los latifundios) no difieren de los campesinos. En buena medida se trata, como ya señalamos, de momentos distintos del ciclo anual de la vida campesina en las condiciones de la Cuenca. Los "trabajadores temporales" pueden agregarse a un latifundio $y$, de manera temporal, en ciertas épocas (cosechas, etc.), desempeñar tareas remuneradas en otro; o pueden ser minifundistas que, pasada la época de su zafra, se emplean temporalmente en los grandes predios. ${ }^{29}$

Según las cifras del cuadro 4, el complejo latifundio-minifundio parece reducirse, por una parte, a predios de 500 hectáreas y más, con elevadas proporciones de grandes propietarios, empleados permanentes y moradores, o de otra condición; y por otro, predios de hasta cinco hectáreas, con predominio de arrendatarios y familiares no remunerados: los de 5 a 500 hectáreas, parecerían así escapar al "complejo" de áreas intermedias.

El mismo cuadro también sugiere que la línea divisoria está dada por la clase de 5 a 100 hectáreas, en caso de tomar como referencia la "media" (columna total) de la Cuenca. La dificultad para trazar una línea de división evidencia que el complejo latifundio-minifundio es una forma estructural específica, donde los tamaños de los predios nada dicen cuando no son considerados en la dinámica de la economía rural. La economía comercial (véase el cuadro 2) abarca $27 \%$ de la superficie de los predios de 5 a 100 hectáreas, al mismo tiempo que la de subsistencia, $70 \%$ del número de establecimientos de esta misma clase; la explotación de subsistencia toma aquí el lugar de los que constituyen la parte más prominente del latifundio (ganado y carnauba) relación que tiende a invertirse en la clase de superficie mayor; mientras que la menor (hasta cinco hectáreas) la de subsistencia logra su expresión máxima. Ese juego de líneas productivas y, por lo tanto, de economías, caza con el juego de la temporalidad de las tareas agrícolas y de extracción, al permitir la rotación de la mano de obra y, por consiguiente, la transformación de las personas en las diversas categorías censales del personal ocupado. En

28 Nótese como característica básica de los "familiares no remunerados" (datos para la Cuenca en 1970) que $41 \%$ de los hombres y $31 \%$ de las mujeres tenían de 10 a 14 años; si agregamos a los niños, jóvenes hasta 19 años, casi agotamos esta mano de obra familiar, ya que sólo queda por agregar una parte de las mujeres adultas.

$29 \mathrm{La}$ elevada proporción (más de un tercio) de personas del sector agropecuario que en la semana anterior al censo de 1970 estaba trabajando en "otra ocupación", diferente de la habitual, corrobora esta interpretación sobre la naturaleza de los "empleados temporales". 
este sentido, las clases de áreas "medias" no pasan de los tamaños físicos posibles que el "complejo" puede soportar. ${ }^{30}$

La hemogeneidad del trabajo, el conjunto de tareas, la metamorfosis de la fuerza de trabajo, se constituyen como garantía de la base de la estructura agraria de la Cuenca, ya que latifundio-minifundio se miden y resisten frente a las violentas oscilaciones del mercado. Éstas se resuelven en el interior de las relaciones de producción, entre la masa campesina y la clase de los grandes propietarios.

En el análisis de la estructura agraria de la Cuenca del Parnaíba se procura demostrar que el modo de vida campesino es un fenómeno integrante del proceso de acumulación en Brasil. Este proceso no revoluciona necesariamente las relaciones de producción, ni las fuerzas productivas, de modo homogéneo en todas las áreas agrícolas del país. Si bien mantuvo relaciones de producción "tradicionales" provocó un aumento de la masa de productos.

El estudio del desarrollo del modo de producción capitalista encuentra en la Cuenca la verificación de la Ley que rige su desarrollo, la ley de "desigualdad del ritmo" en las palabras de Trotsky. En el proceso de trabajo reinante en la Cuenca, el capital no impuso su lógica implacable -que implica la existencia del trabajador libre subordinado al trabajo terminado que necesita alimentarse de aquél, de manera cotidiana, para crecer, lo que ya se hace en la industria y en ciertas áreas agrícolas, lo cual muestra que el modo de producción es capaz de combinar procesos de trabajo diversos, según su ritmo.

\section{Los "Bóias-frias" de la alta Sorocabana de Assis ${ }^{31}$}

En los inicios del siglo la cultura del café se introduce en la región de Assis proveniente de las tierras agotadas del este. Son grandes hacien-

30 Queda oculto todavía en esta maraña algo a ló que ya hicimos referencia: la cuestión de la propiedad de la tierra. Un mismo sujeto puede ser propietario de varios predios "pequeños" y "medianos" y colocar en ellos un morador o administrador. En la región agrícola de Picos, por ejemplo, llamada.Baixão, área natural y accesible para la agricultura, existen pocos latifundios; "en compensación -observa el autor de Picos e Sua Região... - raro es el hacendado que posee una sola propiedad en la región: lo normal es poseer varias pequeñas propiedades (10 a 100 hectáreas)".

31 Bóia-fria, es la denominación que recibe en la región la parte considerada como la más característica de los trabajadores agrícolas. Son personas reclutadas diariamente en los "barrios rurales" y en las periferias de las ciudades para trabajar en las haciendas. Su aparición es reciente y está relacionada con la extinción de los colonos. Los bóias-frias (hombres, mujeres, niños) reciben pago monetario por día de servicio prestado. Aunque pesen las exigencias legales actualmente en vigencia, la gran mayoría de ellos no poseen "cartilla de trabajo", seguro social, garantía de un salario mensual y regulación de horas extras. Sobre el tratamiento y la sistematización del estudio de esta área, véase la nota 4. 
das dedicadas de manera directa a la comercialización; la obtención del producto resulta de relaciones de producción específicas, configuradas por el propietario (el hacendado) y los colonos. En el régimen del "colonato", al mismo tiempo que se propiciaba al trabajador determinado ingreso monetario, salario, se le permite el uso de la tierra intercalada en el cafetal o fuera de él, obteniendo así alimentos y animales en pequeño monto.

La ocupación de la región, incentivada por el café, fue luego seguida por el sistema vial, en esencial el ferrocarril. En 1914 la línea de ferrocarril llega a Palmital, municipio al sudeste de Assis; en 1915, a Assis y en 1916 a Paraguaçu Paulista -todos municipios de la región estudiada.

La crisis de 1929-1931 es un marco de extrema importancia en el desarrollo de la plantation del café; queremos llamar la atención sobre su incidencia en el surgimiento de otros productos de tipo comercial. En la región de Assis, entre otras, la crisis propicia el cultivo del algodón. ${ }^{32}$ Hay entonces concomitancia entre los aumentos de la mano de obra para las actividades agrícolas y del número de propiedades menores que la original, lo que hace pensar al menos que durante algún tiempo las unidades del café se dividieron en unidades de menor dimensión.

La colonización, en los años 30-40, avanza más hacia el oeste y también hacia el sur, hasta alcanzar las tierras fértiles del norte del Paraná.

En el decenio 1940-1950, el crecimiento vegetativo fue de $2.2 \%$ aumentado en $\mathbf{0 . 7} \%$ por la inmigración. ${ }^{33} \mathrm{~A}$ partir del decenio de los 50 cesa la corriente inmigratoria, lo que indica el avance del frente pionero arriba señalado. Entre 1950 y 1960 y también en el decenio siguiente, el crecimiento vegetativo aumenta hasta $2.6 \%$ y después a $2.8 \%$; el flujo migratorio, por el contrario, de $-1.5 \%$ pasa a $-1.8 \%$. El campo pierde esa gente, al mismo tiempo que los principales núcleos urbanos de la región aumentan, demográficamente, en más de $100 \%$ en los últimos 20 años (véase el cuadro 5).

Los cambios expresados por variaciones de la población deben ser considerados en el contexto de la economía del sudeste Brasileño (São Paulo, Río de Janeiro, Minas Gerais y Paraná), en el cual, encontramos amplia y profunda división social del trabajo entre campo y ciudad y

32 Sobre cómo la crisis alcanza al sector cafetalero, en términos generales, podemos decir lo siguiente: casi cuatro zafras abundantes, a partir de 1926-1927, aumentan enormemente la oferta mundial del café; al mismo tiempo (a partir de 1929) la demanda mundial se retrae de manera drástica; esta situación se manifiesta de inmediato bajo la forma de dificultades financieras de los plantadores. Sobre este asunto consúltese Annibal V. Villela y Wilson Suzigan, Politica do Go verno e Crescimento da Economia Brasileira, 1889-1945, en especial el capítulo VI inciso 6.3.2., "Economia e Política do Café", Rio de Janeiro, IPEA/INPES, 1973, Monografía Núm. 10.

${ }^{33}$ Los datos fueron extraídos del Diagnóstico - $11^{a}$ Região Administrativa Marilia, Secretaría de Economía y Planeación del Estado de São Paulo, 1972. 
Cuadro 5

INDICE DE VARIACIÓN DE LA POBLACIÓN DE LOS PRINCIPALES NÚCLEOS URBANOS DE LA REgIón dE ASSIS

\begin{tabular}{lccc}
\hline Ciudades & $\begin{array}{c}1950 \\
\text { (absolutos) }\end{array}$ & $\begin{array}{c}1960 \\
\text { (Indice) }\end{array}$ & $\begin{array}{c}\text { i970 } \\
\text { (Indice) }\end{array}$ \\
\hline Assis & 16675 & 181 & 279 \\
Candido sota & 3721 & 164 & 241 \\
Palaital & 3448 & 187 & 231 \\
Paraguaçu Paulista & 6562 & 174 & 203 \\
\hline
\end{tabular}

Fuente: Diagnóstico - 11a Región Administrativa.

en el propio campo.34 De la población total de la región de Assis, como ya se observó, $51 \%$ está en las ciudades, lo que vale como indicador de la penetración del capitalismo en el campo -a diferencia, por tanto del mismo indicador en la Cuenca del Parnaíba. El incremento de los flujos emigratorios del campo en dirección a los núcleos mayores (u otras áreas agrícolas próximas), se debe tanto a factores de estancamiento, en el lenguaje de Paulo Singer, como de cambio. ${ }^{35}$ Se trata ya de una dominación efectiva creciente del capital en la esfera productiva. Sin embargo, ese proceso de subordinación del trabajo al capital requiere de un examen cuidadoso, el pasaje del colonato a los bóias-frias puede reproducir dis. torsiones, por lo que las relaciones de producción merecen considerarse por separado.

Se intentará un análisis del cambio a través de las estadísticas disponibles. Básicamente se debe ponderar la pérdida de importancia del café y sus sustitución por trigo, soya y caña, como respuesta de las unidades de producción a las oscilaciones del mercado, a las cuales se encuentran sujetas al estar orientada cada vez más su reacción por la racionalidad capitalista. Los establecimientos aumentaron su número en $14 \%$ y su área en $5 \%$. De manera concomitante, el número de predios con cultivos permanentes se redujo en más de $21 \%$ y su área $52 \%$; al paso que los predios con cultivos temporales aumentaron su número en $12 \%$ y poco más de $33 \%$ su área (véase el cuadro 6 ).

Una economía de mercado busca, dentro de ciertos plazos posibles a sus operaciones productivas, mantener o cambiar su estructura de producción - es evidente que según sus disponibilidades (rentabilidad, precios, etcétera); en el caso se trata en esencia de la tierra, como se puede constatar por las entrevistas: un gran propietario (más de 500 hectáreas)

34 Un análisis histórico cuidadoso fue realizado por Paulo Singer en Desenvolvimiento económico y evolución urbana, México, Siglo XXI Editores, 1975, en especial el cap. 2 que trata de la división del trabajo entre la capital de São Paulo y el interior, a partir del café.

35 Véase la nota 14. 


\section{Cuadro 6}

Evolución de las Superficies de LABOR EN LA Región de Assis, $1960-1970$

\begin{tabular}{lrr}
\hline & 1960 & 1970 \\
\hline Establecimientos & 10178 & 11547 \\
Superficie totaiff & 616080 & 645168 \\
Tiexras de labor peroanentes & & \\
$\quad$ Establecimientos & 3643 & 2874 \\
$\quad$ Superficieg/ & 55817 & 26817 \\
Tierras de libor temporales & & \\
$\quad$ Listableciufientos & 8006 & 8931 \\
Superficief & 97487 & 130042
\end{tabular}

Fuente: Censo agrícola, 1960 y Sinópse Preliminar do Censo Agricola, 1970.

a Incluye tierras improductivas (hectáreas).

\%ectáreas.

puede cambiar el café por caña, lo que un pequeño propietario (20 hectáreas) no puede hacer "nada más porque sí", pues tal operación implica financiamientos que requieren la hipoteca de la tierra.

Si hasta los años 30 predominaba el cultivo del café, cultivo permanente, los datos del último decenio (1960-1970) indican con claridad la pérdida de ese predominio en favor de los cultivos temporales. Se registró un rompimiento total del "monocultivo" cafetalero en respuesta a las nuevas condiciones en favor de la caña, soya y trigo, principalmente (véase el cuadro 7).

\section{Cuadro 7}

Distribución del ÁREa cultivada por categorías de productos EN LA Región de Assis, 1961-1970 a

\begin{tabular}{|c|c|c|c|c|c|c|}
\hline Categorias & 1961 & 1967 & 1968 & 1969 & 1970 & $\begin{array}{c}\text { Media del } \\
\text { decenio }\end{array}$ \\
\hline 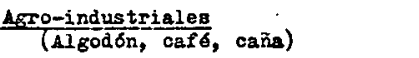 & 55.8 & 22.6 & 32.2 & 44.8 & 32.4 & 39.0 \\
\hline$\frac{\text { Cereales }}{\text { (Arroz, frijol, maiz, trigo) }}$ & 29.2 & 58.8 & 46.4 & 40.9 & 47.4 & 41.9 \\
\hline 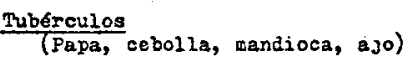 & 5.9 & 12.5 & 16.1 & 12.3 & 9.2 & 12.5 \\
\hline $\begin{array}{l}\frac{\text { Oleoginosas }}{\text { (Cacahuate, girasol, semilla - }} \\
\text { de risino, soya) }\end{array}$ & 8.0 & 5.4 & 4.3 & 3.4 & 8.1 & 5.6 \\
\hline
\end{tabular}

Fuente: Diagnóstico - 11: Región Administrativa.

a Lo que falta en las columnas para $100 \%$ corresponde a frutas, hortalizas y legumbres; no se incluyen los datos para todos los años ya que el café altera de manera sustancial su participación a partir de 1966, además de que esto permite concentrar la atención en los procesos de nuestro interés. 
Cuestiones del mercado mundial (otros productores, oferta excesiva, caída de precios) junto con cuestiones internas (aumento del ágio sobre el café; restricción de la producción; eliminación de cafetales antiguos; ${ }^{36}$ mayores oportunidades lucrativas con otros productos como la soya y la caña, y en fecha más reciente con el trigo), explican la sustitución del café-por cultivos temporales que ofrecen mayores oportunidades lucrativas. De este proceso surge de manera nítida la necesidad del comportamiento capitalista racional, lo que implica pensar en los costos de producción, o sea, en el mejor aprovechamiento de los medios de producción, eliminándose todo lo superfluo. La expansión de las fuerzas productivas, en este contexto, implica erradicar el peso de las "antiguas" relaciones de producción, basadas en el "colonato".

Dejemos, por tanto, explícitos los cambios de la estructura productiva, al desglosar el cuadro anterior en ciertos productos que las estadísticas permiten (véase el cuadro 8).

\section{Cuadro 8}

Volumen DE PRODUCCIÓN DE LOS PRINCIPALES PRODUCTOS EN LA Región de Assis

(millares)

\begin{tabular}{|c|c|c|c|c|c|}
\hline Productos & 1361 & 1967 & 1968 & 19069 & 1970 \\
\hline $\mathrm{CaPs}^{\mathrm{a}}$ & 290 & 146 & 115 & 202 & 58 \\
\hline Algodong & 2033 & 855 & 1011 & 3274 & 2184 \\
\hline Cariaj & 606 & 913 & 847 & 891 & 920 \\
\hline $\operatorname{Arroz}$ & 211 & 367 & 291 & 402 & 586 \\
\hline $\operatorname{lias}^{\mathbf{a}}{ }^{\prime}$ & 766 & 968 & 1139 & 946 & 1577 \\
\hline Semtlla de ricinof & 3.46 & 84 & 87 & 115 & 430 \\
\hline
\end{tabular}

Fuente: Diagnóstico - 11: Región Administrativa.

a Sacos de 60 kilogramos.

b Arrobas.

c Sacos de 25 kilogramos.

En la actualidad (1972-1974) según se verificó en el área a través de las entrevistas, se registra un salto significativo de la soya y el trigo. Lo que no implica que el café no "retorne" y ocupe de nuevo buena parte del área cultivada y del volumen de producción; por lo tanto, su "retorno" se dará con otras relaciones de producción (sin embargo, esta hipótesis implica una cuidadosa política gubernamental). Lo que se desea es resaltar el hecho de que las oscilaciones del mercado. repercutieron, casi de inmediato, en la esfera productiva agrícola, lo que demuestra que tam-

36 La eliminación se efectúa desde antes; en 1962 la erradicación alcanzó a $17.4 \%$ de los cafetaleros en producción en el estado de São Paulo, en 1964, se reduce a $3.2 \%$ y se eleva en 1966 a $6.4 \%$. Periódico El Estado de São Paulo, 1 ? de julio de 1967. 
bién el campo tiende a acompañar al mercado y por lo tanto, el capital aplicado a la tierra surge como parte del capital social total.

La evolución del valor de la producción, que aparece en el cuadro 9, si bien muestra al café agregado a la caña y al algodón bajo la categoría de "agroindustrial", permite "ver" el aumento de la producción del trigo y la soya que sobrepasan la del café.

\section{Cuadro 9}

Distribución porcentual del valor de la pRoducción de las PRINCIPALES CATEgorías EN LA REgIÓN DE ASSIS

\begin{tabular}{lrrrrrr}
\hline Categorias & 1961 & 1967 & 1968 & 1969 & 1970 & $\begin{array}{c}\text { Wedia del } \\
\text { decenio }\end{array}$ \\
\hline Agro-induetriales & 70.5 & 59.3 & 62.9 & 73.3 & 48.3 & 65.9 \\
Corealos & 23.7 & 37.4 & 32.9 & 24.7 & 43.5 & 29.9 \\
Oleoginosas & 5.8 & 3.3 & 4.2 & 2.0 & 7.7 & 4.2 \\
Total & 100.0 & 100.0 & 100.0 & 100.0 & 100.0 & 100.0 \\
\hline
\end{tabular}

Fuente: Diagnóstico - 11ạ Región Administrativa.

El mercado de los principales productos está constituido además del productor individual o cooperativistas y posibles pequeños compradores, por los monopolios internacionales (Anderson Clayton, Sambra Coimbra) y el Estado. En el caso del trigo el Banco de Brasil es el único comprador para vender a los molinos.

Como las aplicaciones de capital se dirigen a los cultivos de algodón, café, caña, trigo y soya, a los cuales está ligado el paso de colono a los bóias-frias, todo lleva a creer que arroz, frijol, papa, y yuca se obtienen bajo relaciones de producción con predominio de los aparceros. Es evidente que las estadísticas disponibles no permiten deducciones tajantes a este respecto; se necesitaría de combinaciones específicas (producto/ tamaño de los establecimientos/condiciones del productor, por ejemplo); una distinción tal es importante en el caso que consideremos los costos de reproducción de la fuerza de trabajo rural, el aprovechamiento productivo de la tierra, la capacidad de ciertos productores de negociar con ventaja, pues una cosa es operar de manera básica con trigo, soya, café, etcétera, en un área de 50, 100 o más hectáreas, donde la yuca, arroz, etc., son cultivos secundarios desde el punto de vista de las operaciones de mercado de la empresa agrícola, y otra cosa distinta es plantar maíz, frijol, soya, yuca, etc., si se dispone tan sólo de 20 hectáreas. La capacidad de seguir el juego del mercado (venta de los productos) y el juego de los costos de producción difieren de manera radical. El productor con predio mayor, además de operar con varios productos y con elevada tecnificación, aprovecha las oscilaciones de los precios alterando la línea productiva, usa fuerza de trabajo del todo carente de tierra (bóias-frias) y la usa sólo el tiempo y en la cantidad que la necesita; lo cual quiere 
decir que el costo de reproducción de la fuerza de trabajo no "compromete" el funcionamiento de la unidad productiva. Las combinaciones de cultivos (las plantaciones secundarias) son contados, prácticamente, como ganancias extras. Para el productor-propietario que dispone de poca superficie, tales combinaciones - frijol, maíz, arroz, etc.- identifican la naturaleza de su existencia en ese contexto agrícola. Para sobrevivir en él, depende del monto de productos que consigue colocar en el mercado, monto que se relaciona con una gran cantidad constante de trabajo, ya que sus posibilidades de tecnificación son prácticamente nulas. El trabajo que puede movilizar, ponderada su reducida capacidad de endeudamiento (para obtener préstamos) es básicamente de cuño familiar (su familia más la de algún aparcero); la naturaleza de ese trabajo no libre y, por tanto, la reproducción de esta fuerza de trabajo, "compromete" el funcionamiento de la unidad productiva.

Si se considera que la penetración del capital en la producción agrícola de la región de Assis tiende de manera abrumadora a extirpar los elementos restantes del colonato, al presionar el cambio de la estructura productiva, la penetración de las reglas del juego del mercado en el interior de la hacienda y la uniformidad del precio de la fuerza de trabajo, igualan campo y ciudad. Al mismo tiempo, esa tendencia dominante, al negar el colonato, no destruye del todo cierto tipo de trabajo familiar (pequeño propietario, aparcero).

Como puede observarse en el cuadro 10 , entre 1960 y 1970, el área media de los establecimientos propios pasó de casi 69 hectáreas a 85; la de los arrendatarios aumentó de 13 a 18, mientras que la de los ocupantes permaneció en 23 hectáreas y la de los aparceros; en 1970 era de 11. Las tres últimas categorías de productores, absorben poca superficie $(12 \%$ del total) pero son importantes en cuanto al número de establecimientos ( $42 \%$ dẹl total). Todo esto lleva a creer que el arrendamiento haya ampliado su área de acción (ya predominante en 1960); el aumento del área media constituye un indicador de la superficie mínima para operarse en ella relaciones de producción capitalistas puras. Es evidente que hay diferencias de arrendamientos, por lo que el área media constituye un simple indicador.

Entre los propietarios se debe distinguir los que cuentan con áreas pequeñas y con áreas mayores; sin embargo, sólo se dispone de las Estadísticas Catastrales, del INCRA, de 1972, que podemos relacionar con las fuentes del cuadro 10 . Si se acepta la clasificación de minifundios del INCRA ${ }^{37}$ para la región de Assis, obtenida por la relación área/establecimientos, se obtiene una media aproximada de 20 hectáreas. Esta cifra

37 El INCRA clasificó los predios según cierto "módulo": la menor unidad de superficie manejada por una familia de seis miembros, que permita llevar a cabo determinado tipo de exploración agrícola y posibilitar el bienestar económico y social a los que en ella trabajan. De esa clasificación resultan cuatro tipos: minifundios, empresa rural, latifundio por explotación y latifundio por dimensión. 
Cuadro 10

Condición de los productores en la Región de Assis

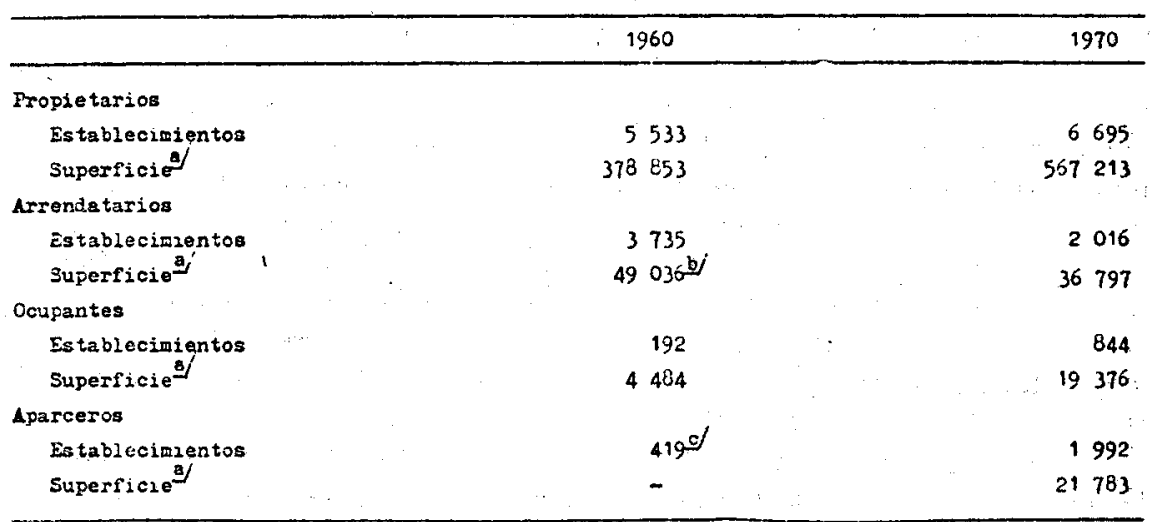

Fuente: Censo Agricola, 1960 y Sinópse Preliminar do Censo Agricola, 1970.

a Hectáreas.

b Existen municipios (Campos N. Paulista y Palmital) en los que los pagos en especie en este año son sensiblemente mayores a los pagos en dinero.

c En 1960, el Censo consideraba al administrador, al contrario que el aparcero, en la condición de productor. 419 es el número de establecimientos con aparceros (al parecer los administradores de 1960 - 718 establecimientos con una superficie de 183688 hectáreas - se sumaron a los propietarios en 1970).

es congruente con las informaciones obtenidas a través de entrevistas: hasta de 10 "alqueires" (24 hectáreas) se consideran pequeña propiedad. Con tal criterio y el número de establecimientos con su área respectiva de hasta 20 hectáreas se obtienen las cifras del cuadro 11.

No es posible obtener cruzamientos entre clases de área y condición del productor; pero, en relación a los establecimientos (predios) hasta de 20 hectáreas ¿se trata en realidad de minifundios? En 1960 el área media de los predios era de nueve hectáreas y en 1970 de 19. Incluso si se

\section{Cuadro 11}

ESTABLECIMIENTOS POR TAMAÑos DE SUPERFICIE EN LA REgióN DE ASSIS

\begin{tabular}{|c|c|c|c|c|}
\hline \multirow{2}{*}{ Ano } & \multicolumn{2}{|c|}{ Hasta 20 hectirreas } & \multicolumn{2}{|c|}{20 y más bectareas } \\
\hline & Satablecimiantos & Superficio & Establectmientos & Superticie \\
\hline 1960 & 5780 & 52570 & 4398 & 563502 \\
\hline 1972 & 4902 & 94074 & $3060^{2}$ & 590966 \\
\hline
\end{tabular}

Fuente: Censo agricola, 1960 y Estadísticas Cadastrais 1, INCRA, 1972.

a El INCRA utiliza el concepto de inmueble, tipo de propiedad rural que en 1972 es de 7962. El establecimiento (terreno sujeto a una sola administración sea por parte del propietario o del arrendatario, etc.) es distinto al inmueble (propiedad rural, que puede contener más de un establecimiento). 
tiene en cuenta la posibilidad de error - debido a la distinta conceptualización - el área absoluta de ellos entre las dos fechas, casi se duplicó. ${ }^{38}$

Se observa, por lo tanto, un aumento del área media de las pequeñas unidades de producción (establecimientos o predios) que puede ser de propietarios, arrendatarios, ocupantes o aparceros. Interesa distinguir la tendencia de aumento del área relativa en los dos primeros grupos. En cuanto al pequeño popietario, se torna difícil hablar de minifundio según la terminología del INCRA ("bienestar económico y social", etc.) ya que su modo de vida se halla envuelto por determinadas relaciones de producción (propiedad pequeña y trabajo familiar) que frenan el desarrollo de las fuerzas productivas. En cuanto al arrendamiento, realizado por regla por propietarios que ya poseen áreas mayores, si su tamaño lo sitúa como minifundio, la posibilidad de usar máquinas e insumos industriales, ${ }^{39}$ permiten superar el freno representado por el tamaño -y son otras las relaciones de producción que presiden el desarrollo de las fuerzas de producción.

\section{Cuadro 12}

Personal ocupado en la Región de Assis a

\begin{tabular}{|c|c|c|c|c|c|c|}
\hline \multirow{2}{*}{ Año } & \multirow{2}{*}{ Total } & \multirow{2}{*}{$\begin{array}{l}\text { Miembros no } \\
\text { remunerados de } \\
\text { la familia }\end{array}$} & \multicolumn{2}{|c|}{ Enpleados } & \multirow{2}{*}{ Aparceros } & \multirow{2}{*}{ Otre condición } \\
\hline & & & Permanentes & Iemporales & & \\
\hline 1960 & 49466 & 25912 & 12673 & 7911 & $\begin{array}{l}2217 \\
(419)\end{array}$ & 753 \\
\hline 1970 & $38 \quad 183$ & - & - & - & (1 992) & - \\
\hline
\end{tabular}

Fuente: Censo agrícola, 1960 y Resumen preliminar, 1970.

a Para 1970 sólo se registra el total de personal ocupado. Los aparceros (que aparecen entre paréntesis) corresponden al número de establecimiento en condición de productores; el número entre paréntesis que corresponde a 1960 se refiere a los establecimientos con aparcería (los 2217 se refieren a los aparceros junto con los miembros de sus familias que trabajan).

38 Veamos las consideraciones y cálculos del Diagnóstico. El INCRA determinó el módulo medio por municipio con base en el tipo de explotación, distancia del mercado, inversión en los predios, infraestructura municipal, etc. A través de una ponderación de los módulos, en los municipios integrantes de la región, la publicación gubernamental llegó a un módulo regional de 42.2 hectáreas (por consiguiente, más del doble del módulo minifundista). Los predios hasta de 50 hectáreas en 1960 alcanzan $70 \%$ de los establecimientos y $19 \%$ de la superficie total, respectivamente; los establecimientos de 50 y más hectáreas, complementan el cuadro. Lo anterior confirma grosso modo la tendencia al aumento de las áreas menores.

39 De 1963 a 1970, los préstamos concedidos en la región de Assis a la producción (agropecuaria e industrial), en valor constante, aumentaron de casi 30 millones de cruzeiros hasta más de 55; de éstos, alrededor de $75 \%$ se destinaron a la agricultura. Por otro lado, si en 1960 apenas $2.8 \%$ de los establecimientos utilizaron fuerza mecánica, en 1970,12.2\% disponen de tractores. Datos del Diag-

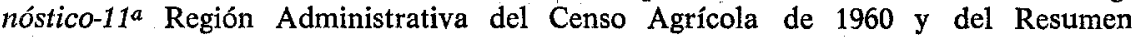
de 1970. 
Consideremos ahora la distribución del personal ocupado (véase el cuadro 12).

Si se tienen presentes los resultados del análisis -aumentos de la producción, de los créditos, del capital constante - la disminución del total del personal ocupado no causa extrañeza. Su disminución del $23 \%$ resulta de la alteración de la composición orgánica del capital en el siguiente sentido: aumento del capital constante en relación al capital total; pero de igual modo ocurre un aumento del capital variable bóia-fria gracias al desplazamiento del colono (el precio de la fuerza de trabajo bóia-fria es integralmente monetarizado).

En 1960, 62\% de los empleados eran permanentes. Si se considera que en esa fecha predominaba el cultivo del café en términos del área cultivada (más del 50\% del área estaba ocupada por la "agroindustria") y que casi $30 \%$ del área cultivada de "cereales" (arroz, frijol, maíz) era trabajada por aparceros, los de otra condición y parte por las arrendatarios, se puede afirmar que la gran mayoría de tales empleados permanentes eran colonos. ${ }^{40}$ Los trabajadores temporales, que pueden ser considerados como bóias-frias, operarios rurales, suman 38\% de los empleados. Este porciento debe haber aumentado de manera considerable de 1967-1968 en adelante, por las posibilidades de "modernización" del cultivo cafetalero (propiciado en parte por la "erradicación") y de la agricultura en general por la asistencia técnica ("casas de agricultura"), a través de las oportunidades alternativas de lucro con otros cultivos (trigo, soya, caña), del aumento de la aplicación del capital y por la extensión de la legislación del trabajo de la ciudad al campo. Después volveremos sobre este tema.

En cuanto a los aparceros, todo conduce a pensar que su número aumentó. Si en 1960 había 2217 en 419 establecimientos (media de 5), en 1970 son casi 10000 (1992 establecimientos $\times 5){ }^{41}$ Se requieren aquí algunas consideraciones. En 1960 había alrededor de 5.7 miles de establecimientos menores de 20 hectáreas; en esa misma fecha el censo registraba 6.7 miles de establecimientos sin personal contratado, o sea, sin empleados aparceros o moradores; lo ctial quiere decir que eran "operados" por un pequeño propietario o un aparcero o un arrendatario -ayudados sólo por la familia - y representaban $66 \%$ del total de los establecimientos. También en esa fecha, 2.6 miles de establecimientos (29\%) tenían una superficie cultivada de hasta cinco hectáreas; en una superficie tal no se cultivaba café, caña, soya, trigo y, difícilmente algo-

40 Sobre la transición del trabajo esclavo al del colonato y a la situación de este último en la economía cafetalera existen varios trabajos. Muy sugestivos son los de: T. H. Holloway, "Condições do mercado de trabalho e organização do trabalho nas plantações na economia cafeeira de São Paulo, 1885-1915" en Estudos econômicos, vol. 2, Núm. 6, pp. 145-180, 1972; y el de A. Castro, Sete ensaios de economia, vol. 2, Forense, São Paulo, 1971.

$\$ 1$ Bajo la hipótesis de que se mantiene la misma media de cinco aparceros por establecimiento. 
dón, arroz, frijoles, yuca, papas, componentes básicos de la canasta de consumo del trabajador, tanto rural como urbano. Por lo que ya se dijo antes, no es descabellado pensar que la fuerza de trabajo para esos cultivos sea la del ocupante (estadísticamente son pocos), colono y del aparcero. La mezcla de tipos de trabajadores en ciertos cultivos - de manera notoria en los alimenticios- permite pensar que los estancamientos provocados por las oscilaciones del mercado (para esos cultivos) no permiten el uso exclusivo de sólo fuerza de trabajo asalariada. Lo que restituye la importancia de esas categorías ${ }^{42}$ (datos de 1970). Es sintomático en las entrevistas la figura del "falso mediero" (o falso aparcero) o la del "arrendatario al 30\%" (aparcero) que surgían en las conversaciones. De hecho, es fuerza de trabajo para el propietario, cuyo valor de reproducción bajo forma monetaria y dentro de los cánones se muestran no sustentables para el propietario (no sustentables en los cuadros en que la empresa es dirigida; esto quiere decir que un cambio del tipo de fuerza de trabajo acarrearía un cambio en la organización general de la unidad productiva).

Del estudio de las estadísticas disponibles se puede concluir así que:

a) El número de propietarios aumentó cerca de $20 \%$ en cuanto que el área de sus establecimientos aumentó $50 \%$; de igual modo, el número de aparceros aumentó, pero no es posible determinar la evolución de la superficie; el número de arrendatarios disminuyó, si bien su área media aumentó de 13 a 18 hectáreas; ya en 1960 predominaba el arrendamiento por dinero, forma que de 1970 en adelante tiende a dominar de manera completa, lo cual quiere decir que se trata cada vez más del arrendamiento capitalista; los ocupantes o los que poseen tierra, que nada pagan por su uso, aumentaron en número y superficie, lo que posiblemente indica una forma de presión sobre la tierra asignada en un cuadro bastante definido de la propiedad de la tierra, por el uso de las menos fértiles; por su existencia y evolución pueden considerarse como una capa de pequeños productores de mercancías, ${ }^{43}$ insertados en una actividad agropecuaria que tiende a la completa subordinación del trabajo al capital. Se tiene de esta manera, por un lado, a los pequeños propietarios en establecimientos de hasta 20 hectáreas, con hasta cinco cultivadas $\mathrm{y}$, de otro, propietarios con establecimientos de área mayor, con más de cinco hectáreas cultivadas. ${ }^{44}$ Los arrendamientos aparecen en este contex-

42 En años recientes, afirma E. Feder a propósito de la fuerza de trabajo en el cultivo del café paulista, el número de asalariados agrícolas aumentó de 222000 a 281000 , entre 1955 y 1960; pero también los aparceros y colonos aumentaron de 514000 hasta 527000 , aunque a tasa menor que los asalariados. Véase "Latifundio and Agricultural Labour in Latin America", en Teodor Shamin (Comp.), Peasants and Peasant Societies, Inglaterra, Penguin Books, 1971, p. 93.

43 Véase Juarez R. B. Lopes, "Desenvolvimento e estrutura agrária do Brasil", CEBRAP (mimeografiado).

44 Es claro que tales números no tienen ningún "encanto" en la determinación de los grupos sociales; se trata de un modo de aprovechar las estadísticas. 
to como una ampliación del área cultivada, propiedad de los establecimientos mayores y la aparcería surge como una forma renovada del colonato, producida por dificultades de mercados que imposibilitan al propietario instaurar el circuito de determinación capitalista real de modo integral en la esfera productiva, debido al tipo de producto y a las oscilaciones de los precios. En términos generales, tendríamos una capa de "pequeños productores de mercancía" 45 (pequeños propietarios más ocupantes) cuya fuerza de trabajo tendría como base a la familia; la capa de propietarios, burguesía agraria, utiliza fuerza de trabajo de los bóiasfrias fundamentalmente, y de empleados permanentes - pero también de fuerza de trabajo en forma de aparcería;

b) El total del personal ocupado disminuyó 33\%. Con base en los empréstitos crecientes a la agricultura, en la alteración de las líneas productivas y en la legislación del trabajo aplicado al campo, se puede afirmar que, en la actualidad, se presencia una alteración drástica de los datos de 1960 (62\% eran empleados permanentes y 38\% temporales) en favor del aumento de los bóias-frias; éstos como operarios agrícolas, son resultado y premisa de la subordinación real del trabajo al capital.

Se dijo que el aumento de bóias-frias estaba ligado a un elenco de factores, entre otros la alteración de la línea productiva de las empresas rurales, la legislación del trabajador y la seguridad social en el campo. Vamos a desarrollar más estos elementos mediante el material obtenido a través de entrevistas en un intento de centrar la apreciación de los grupos sociales.

Parece haber una fecha común en cuanto a la intensificación del paso del colonato al bóia-fria en la región; se habla por lo general del período 1966-1967 y 1967-1968. Luego se agrega que las reclamaciones de los trabajadores (colonos, medieros, aparceros, arrendatarios a producto) aumentaban por esa fecha. No hay duda en cuanto al papel de la legislación en el proceso que, al instituirse la Cartera del Trabajo y Previsión Social para el trabajador rural, ${ }^{46}$ lo igualaron prácticamente al urbano.

45 La diferencia entre la producción simple de mercancías (en el texto la denominamos de "pequeños productores de mercancías") y "economía campesina", radica en la tendencia a la especialización de la producción de la primera forma de organización económica; aunque su proceso de reproducción, en cuanto a categoría social, pasa por el circuito del mercado.

40 La legislación del trabajo rural en Brasil no es reciente; desde que el café se impuso como producto importante y contó con el concurso de mano de obra no esclava, existen leyes que protegían al trabajador extranjero $(1830,1837$ y 1879 en el Imperio). En 1907, ya en la República, el Congreso vota la ley sobre las "Libretas Agrícolas", que de hecho garantizan al hacendado del café el control sobre la mano de obra: "La libreta es un contrato: el trabajador (el colono), se obliga a vivir un año agrícola en la propiedad donde trabaja y dar un cierto número de días de servicio para la conservación de carreteras, estipula cuánto gana por el cuidado de mil cafetos y por la cosecha, cuánto gana por día de servicio y cuáles son sus regalías", afirma Edgar Carone, en A República Velha, São Paulo, Difel, 1970, p. 245. La legislación, en cuanto a garantía de reinvindicación 
Medieros y colonos, al ser despedidos, reivindican derechos respecto a los que la ley permitía su retroactividad hasta 1960 o 1962; al mismo tiempo comenzaron a exigir parte de su papel real en la aparcería y derechos de empleados (un salario anual suplementario, salario mínimo, vacaciones renumeradas, etc.). No se conoce la extensión del fenómeno, pero ellos existen actualmente (1974) y en mayor proporción que años atrás, como se ha visto por las "quejas de los trabajadores" en los sindicatos (órganos que agrupan pequeños productores sin empleados y a estos últimos). De ese modo, al igualar el precio mínimo de la fuerza de trabajo en el sistema brasileño, la legislación aceleró (y acelera) un proceso en curso, que establece como premisa el resultado real (bóia-fria) de la penetración del capital en la producción agrícola y al tomarlo como resultado, legaliza una de las premisas de la acumulación en la agricultura.

La legislación, incluida la prevención es anterior al proceso de reivindicación de los colonos y medieros (véase la nota 46). Pero la preocupación por el campo, de manera principal el próximo a las grandes concentraciones urbanas hizo que, de manera notoria, a partir de 1969 el Estado empezará a exigir la práctica de las leyes. De esta manera, todo induce a considerar que los fenómenos ligados al cultivo cafetalero son los principales responsables del reacomodo de los grupos y clases sociales en la región. La erradicación como forma de control de la oferta, problemas en los precios mundiales, etc., afectan las perspectivas de los productores desde comienzos de los años sesenta. Entre 1964 y 1967, y aún hasta los setentas, los precios relativos del café sufrieron una caída y aumentó el impuesto cambiario. En este sentido, los propietarios hablan de descapitalización. Las alternativas de cultivos se amplían: algodón, trigo, soya ("lo que decide la plantación es el precio" según uno de los mayores propietarios). Si ya el café y el algodón requieren abonos, insecticidas, etc., los otros productos no sólo aumentan esa exigencia sino que llevan los implementos y máquinas al campo. Según las informaciones recabadas, la expulsión de la mano de obra del interior de las haciendas ocurría (empleo de insumos industriales, aprovechamiento de toda área cultivable, necesidad "temporal" de trabajo) cuando se "inició" el empleo de maquinaria; las condiciones del mercado "exigían" el uso de maquinaria y la legislación vino a acelerar su empleo.

El colono y su familia que disponían de tierras intercaladas en las hileras del cafetal, tienden a ser expulsados de las haciendas.. y a engro-

de los trabajadores rurales, es un trabajo en espera de autor. Si consideramos sólo los años recientes, parece que su incidencia efectiva en el campo se presenta a partir de la actuación de los sindicatos rurales (de pequeños propietarios semiasalariados y trabajadores) y de la legislación de 1969, más incisiva en aspectos de previsión. A partir de éstos, la reivindicación alcanza al salario, horas extras, etc. De manera formal, el decreto de ley del 10 de octubre de 1969, incluye en la Cartera del Trabajo y Previsión Social las referencias de Consolidación de las leyes de trabajo del $1^{\circ}$ de mayo de 1943 y del estatuto del trabajador rural del 2 de marzo de 1963. 
sar las filas del nuevo ejército rural de reserva, y a ser relegados en los "barrios rurales" de pequeñas ciudades y en la periferia de los núcleos urbanos mayores. La conversión de sus costos de reproducción en dinero -legalizados en la "cartera" (salario mínimo, vacaciones-aguinaldo) no es sustentada por todos los propietarios. Los pequeños buscan una forma de aparcería; los propietarios de áreas mayores - según informaciones, $40 \%$ de los más grandes pagan como máximo el salario mínimo y es lo que la aplastadora mayoría de los bóias-frias reciben por día-47 simplemente burlan la ley, lo que parece ser la norma. Y el colono, aparcero y bóia-fria, ante la amenaza real de perder el empleo, aceptan el juego extralegal (de ahí las cautelas al pensar en estadísticas). El aumento del capital constante, la tendencia a expulsar el costo de la fuerza de trabajo del interior de la empresa, al aumentar el nuevo ejército rural de reserva, hace que éste se torne un "autorregulador" de las diversas relaciones de producción, pese al esfuerzo del Estado de dar estatus y derechos de empleado a esa masa. Al mismo tiempo que el colono se transforma en trabajador agrícola, tendencia dominante, se garantiza en áreas y en proporciones pequeñas la ampliación de la aparcería.48

Las empresas monopólicas internacionales desempeñan un papel curioso en ese proceso. Nos referimos aquí de manera específica a una de ellas que, durante buen tiempo, no sólo incentivó la plantación del algodón y cacahuate, sino que proporcionaba asistencia técnica a los hacendados, además de semillas y abonos, es decir, se interesaba de manera directa por la producción. En la actualidad se restringe a la comercialización y al beneficio. Su antiguo papel fue ocupado por el Gobierno a través de la instalación y aumento de "Casas de Agricultura" que ofrecían asistencia técnica, etc.; y a través de financiamientos bancarios (regidos por legislación estatal específica) para la adquisición de maquinaria, implementos, abonos y semillas. Lo que no deja de ser, por un lado, una forma de expulsión de los costos del monopolio y, por otro, de la expulsión de los colonos.

El ingreso a la capital en la producción agrícola maneja la empresa rural; el empleado permanente (para tener una huerta procede ahora a un contrato, por escrito, con el propietario, donde se registra el salario y la "aparcería") no se hace cargo de más de cierto número de cafetos pero están todos a la disposición de la administración central para las diversas tareas; por otro lado, la contratación de bóias-frias depende de

47 Véase más adelante el papel del intermediario ("gato") en la contratación de bóias-frias.

48 A semejanza de lo que se hizo en la nota 19 , cabría preguntar aquí sobre la dinámica poblacional, en especial sobre la reproducción de los portadores de trabajo "colono" y bóia-fria enfocándolos a través de los conceptos de pauperi. zación relativa y absoluta iserá que su comportamiento reproductivo se asemeja al de los campesinos de la Cuenca del Parnaíba? Todo induce a pensar que mo. tivos semejantes (pauperización) provocaron comportamientos reproductivos distintos -hipótesis aún por verificar. 
operaciones urgentes (corte, cosecha, etc.), cuya ejecución sobrepasa la capacidad de los empleados permanentes. La utilización de éstos, sumada a la de aquéllos, se muestra adecuada a las nuevas líneas de producción, en extremo especializadas. Al mismo tiempo, tal utilización de la fuerza de trabajo presupone grandes superficies de tierra. Algunas familias - ligadas al café, ganado, algodón, caña (e ingenio), que son también grandes plantadores de trigo y soya- dominan económica y políticamente la región. Los otros propietarios mayores siguen su ejemplo en la senda del cambio. Esto quiere decir que, instituida la concurrencia entre los capitalistas, se maniobra con el capital variable, de manera principal con aquella parte cuya remuneración es diaria; esta parte reciente de inmediato las oscilaciones del mercado de trabajo: al fin de la cosecha, la empresa no requiere más una fuerza de trabajo numerosa; alteración de las cuotas de los ingenios, etc.

Este nuevo ejército es reclutado diariamente por un contratista denominado gato -contratado por la "hacienda"-, cuyas ganancias "provienen" de la diferencia del precio de la contratación del servicio y del precio de contratación de cada bóia-fria; en el lenguaje del gato, él jala mano de obra para las haciendas. La mayoría de los bóias-frias no tienen "carta de trabajo", seguro de desempleo, salario mínimo, horas extras, como ya se observó; el camión del gato los lleva para la hacienda desde los barrios y periferias por la mañana y al regresarlos por la tarde reciben la diaria. El intermediario debería estar registrado como contratista; en realidad, pocos lo están, si no es que ninguno; ocurre que las grandes haciendas tienen sus gatos de planta, con contratos y premios anuales; además de traer a los diaristas a las haciendas pueden desempeñar la función de vigilancia en el proceso productivo. Por eso, el intermediario se asemeja a un empleado de la empresa; en la mayoría de los casos, él continúa como autónomo.

En este proceso, el pequeño propietario se encuentra maniatado ante la imposibilidad de ampliar su área de producción y así conseguir empréstitos bancarios de importancia y con la posibilidad de convertirse eventualmente en asalariado. Es de las pequeñas áreas de donde proceden los cultivos no mecanizados, como arroz, frijol, maíz, yuca. Su unidad de trabajo es la familia del propietario; con todo, ésta se ve afectada, en el mantenimiento de su reproducción, por las oscilaciones del mercado, al mismo tiempo que necesita, en determinados momentos, de elevado número de trabajadores, lo que implica utilizar jornaleros; de esta manera, el pequeño propietario se favorece de la situación general "creadora" del ejército rural de reserva, apropiándose de su (ejército rural) trabajo excedente. Pero tal uso requiere disponibilidad monetaria, no siempre a su alcance; como consecuencia, se recurre a la aparcería y al cambio de días de servicio entre esos pequeños productores. La tierra no significa para ellos un simple medio de obtener capital, pues las fuerzas pro. ductivas se hallan restringidas, prensadas por las relaciones de producción 
basadas en la forma de pequeña propiedad que tiene en cuenta la reproducción de la familia en una dinámica económica en que las relaciones con el mercado integran la reproducción de esa capa social.

Por otro lado, el aparcero se siente defraudado en su papel - hay buen número de procesos en ese sentido-; no obtienen parcela de los "lucros"; de hecho ocurre que, después de cuatro o cinco años de trabajo, ven que la Cartera acusa elevado saldo deudor. Pero, al parecer, es un proceso aún en marcha; en cuanto a su destino en el campo, sólo tiene dos posibilidades: ocupante, trabajando tierras menos fértiles, o bóia-fria. En lo que se refiere al destino del pequeño propietario, parece que por una parte debería valerse de la aparcería y, de manera evenual, de los jornaleros, así como del aumento de la explotación de la mano de obra de su propia familia y, por otra, valerse de diversas formas de dependencia con propietarios mayores y ocultar entonces su situación de "aparcero".

Se debe resaltar aquí que proporciones respetables de los bienes que componen la canasta de consumo del trabajador urbano y rutal tienen su origen en los aparceros y pequeños productores de mercancía (se pueden agregar los ocupantes); exactamente son esas relaciones de producción las que posibilitan la venta del producto creado por ellas, ya que su precio, que debía ser, en el máximo, igual al del mismo producto generado en las empresas, necesita tener un costo de producción que permita, por lo menos, la reproducción de las condiciones de producción de las unidades organizadas por los pequeños productores y aparceros; y este costo se determina por las relaciones de producción, sin aparecer bajo forma monetaria.

En términos generales, las conclusiones obtenidas del análisis de las estadísticas son semejantes a las obtenidas del estudio del material de campo. La penetración del capital en la esfera de la producción agrícola también acompaña la desigualdad del ritmo del processus histórico, sin homogeneizar a los que trabajan en ese sector. $Y$ esto deben reflejar los conceptos. Burguesía agraria y proletariado rural, son ciertos en términos genéricos; mientras tanto, esta última categoría engloba capas muy diversas, con situaciones y conciencia diversas, de tal modo que la simple apariencia de unidad que sugieren, con dificultad permitirá entender cómo se mueve esa montaña real.

\section{Conclusiones}

A partir de los años treintas, el papel de la agricultura como proveedora de alimentos para el incipiente mercado interno y, de manera notable, como exportadora, se altera en forma radical con el cambio de la base del proceso de acumulación en Brasil, que se centra en el desarrollo urbano-industrial, en especial el industrial. Esta alteración revierte sobre la agricultura al requerir no sólo el pago de los bienes de capital (maquinaria e insumos), la provisión de alimentos para el mercado interno 
en expansión, sino también las masas de trabajadores para las empresas y para el reclutamiento en los cuadros del ejército industrial de reserva.

Sólo tasas elevadas de explotación permitirían la extensión y consolidación de la acumulación basada en la industria; se liga ahí a la alta productividad con bajos costos de reproducción de la fuerza de trabajo, costos éstos de alimentación y de bienes y servicios específicamente urbanos, determinados los primeros de manera básica por el costo de reproducción de la fuerza de trabajo rural. ${ }^{49}$ El Estado, entidad centralizadora y fundamental en este proceso, propicia las condiciones institucionales de la acumulación con tecnología proveniente del exterior, y faculta la ampliación del predominio del nuevo proceso de acumulación, así como su hegemonía en la lucha de clases en el país. En la legislación social estará registrado el aumento de la explotación de la fuerza de trabajo en favor de las clases en las que toma cuerpo el desarrollo económico. El salario mínimo no sólo homogenizó el costo de la fuerza de trabajo urbana en el ámbito nacional, sino que últimamente tiende a englobar a la fuerza de trabajo rural.

Mientras tanto, la redefinición de la agricultura en el proceso global no se vio acompañada, por igual, por las fuerzas productivas y las relaciones de producción de ese sector -como acabamos de ver a través del estudio de dos áreas agrícolas. Se quería enfatizar que la comprensión de las relaciones de producción en el campo brasileño sólo es posible a través de una visión histórico-estructural del desarrollo del capitalismo. Por otro lado, la pura y simple constatación general en nada contribuye a la revelación concreta de estas relaciones. Ni siempre la constatación de que el capitalismo conforma el modo de desarrollo de un país, indica con claridad las diversas formas que ese desarrollo asume, ni en qué esferas de la producción social necesariamente se encuentra del todo desarrollado: se encubren, muchas veces, las peculiaridades, las diferenciaciones, que tal proceso general presenta en las particularidades, pagándose tributo, una vez más, al famoso concepto de progreso.

La subordinación real del trabajador al capitalista sustituye la subordinación formal del trabajo al capital cuando se trata del modo de producción capitalista ${ }^{50}$ lo cual no quiere decir que desaparezca por completo la subordinación formal, así como la producción de plusvalía relativa no destruye por completo la producción de plusvalía absoluta, o, por otra parte, si el capitalismo usurario y el comercial se hallan ligados genéticamente, por lo menos en Europa Occidental, al capitalismo industrial, esto no quiere decir que el desarrollo del capitalismo mundial no recu-

49 El proceso global de acumulación descrito en forma sumaria, con énfasis en el papel de la agricultura, fue analizado por Francisco de Oliveira, en "A economia brasileira: crítica à razão dualista", Estudos CEBRAP 2.

50 Carlos Marx, El capital, México, Fondo de Cultura Económica, 1972, vol. I, cap. XIV, p. 426. 
rre a aquellas formas, en otras áreas, ahora ya como elementos estructurales.

No se entendería la realidad si se viera en el campesinado brasileño un fenómeno anticapitalista como en el trabajador agrícola brasileño, un obrero urbano.

Hay que intentar la identificación de las formas de penetración del capitalismo en la agricultura; "el capital subordina y transforma a su manera esas diversas formas de propiedad" 51 y, en ese proceso, el capitalismo asume diversas formas. Es en el movimiento de esa realidad, cuya desarrollo se muestra ligado, ${ }^{52}$ donde se deben descubrir las clases sociales, esto es, la relación entre los grupos sociales con el capital, con el resultado de esas relaciones que son al mismo tiempo premisa de ellas, y que no siempre aparecen con claridad, incluso cuando se dispone de conceptos amplios como propiedad o no propiedad de los medios de producción, burguesía y proletariado, porque también estos conceptos -si pretenden reproducir el movimiento de la realidad - asumen formas diversas.

Latifundistas y campesinos de la Cuenca del Parnaíba, burguesía agraria y obreros en la Alta Sorocabana de Assis son grupos sociales creados por el capital cuyo centro está en la industria. El proceso de acumulación no necesariamente homogeniza las relaciones de producción mientras las fuerzas productivas respondan de manera adecuada a las necesidades de ese proceso. El fenómeno demográfico es parte de ese movimiento desigual, parte integrante de ese concreto en movimiento, que adopta aquí y ahora formas diversas.

51 "Nuevos datos sobre las leyes de desarrollo del capitalismo en la agricultura", V. I. Lenin, Obras escogidas, Buenos Aires, Editorial Cartago, tomo III, 1973, Fascículo I (el autor se refiere ahí a las formas feudal, de clan, comunal, etc.).

52 "La ley más general del processus histórico es la desigualdad del ritmo ... ley del desarrollo combinado", señala Trotsky en A história da revoluçao Russa, Rio de Janeiro, Ed. Saga, 1967, vol. I, cap. 1. 